\title{
Opposed Jet Burner Extinction Limits: Simple Mixed Hydrocarbon Scramjet Fuels vs Air
}

\author{
Gerald L. Pellett ${ }^{*}$ Sarah N. Vaden ${ }^{2}$, and Lloyd G. Wilson ${ }^{3}$
}

\begin{abstract}
Opposed Jet Burner tools have been used extensively by the authors to measure Flame Strength (FS) of laminar non-premixed $\mathrm{H}_{2}$-air and simple hydrocarbon $(\mathrm{HC})$-air counterflow diffusion flames at 1-atm. FS represents a strain-induced extinction limit based on air jet velocity. This paper follows AIAA-2006-5223, and provides new HC-air FSs for global testing of chemical kinetics, and for characterizing "idealized flameholding potentials" during early scramjet-like combustion.

Previous FS data included six $\mathrm{HCs}$, pure and $\mathrm{N}_{2}$-diluted; and three $\mathrm{HC}$-diluted $\mathrm{H}_{2}$ fuels, where FS decayed very nonlinearly as $\mathrm{HC}$ was added to $\mathrm{H}_{2}$, due to $\mathrm{H}$-atom scavenging. This study presents FSs on mixtures of (candidate surrogate) $\mathrm{HCs}$, some with very high FS ethylene. Included are four binary gaseous systems at $300 \mathrm{~K}$, and a "hot" ternary system at $\sim 600 \mathrm{~K}$. The binaries are methane + ethylene, ethane + ethylene, methane + ethane, and methane + propylene. The first three also form two ternary systems. The hot ternary includes both 10.8 and 21.3 mole $\%$ vaporized $n$ heptane and full ranges of methane + ethylene. Normalized FS data provide accurate means of (1) validating, globally, chemical kinetics for extinction of non-premixed flames, and (2) estimating (scaling by HC) the loss of "incipient" flameholding in scramjet combustors. The $n$-heptane is part of a proposed "baseline simulant" (10 mole $\%$ with $30 \%$ methane $+60 \%$ ethylene) that "mimics" the ignition of endothermically cracked JP-7 "like" kerosene fuel, as suggested by Colket and Spadaccini in 2001 in their shock tube "Scramjet Fuels Autoignition Study." Presently, we use FS to gauge idealized flameholding, and define HC surrogates. First, FS was characterized for hot $n$ heptane + methane + ethylene; then a hot 36 mole $\%$ methane $+64 \%$ ethylene surrogate was defined that mimics FS of the "baseline simulant" system. A similar hot ethane + ethylene surrogate can also be defined, but it has lower vapor pressure at $300 \mathrm{~K}$, and thus exhibits reduced gaseous capacity. The new FS results refine our earlier "idealized reactivity scale" that shows wide ranging $(50 \mathrm{x})$ diameter-normalized FSs for various HCs. These range from JP-10 and methane to $\mathrm{H}_{2}$-air, which produces an exceptionally strong flame that agrees within $\sim 1 \%$ of recent 2-D numerically simulations. Finally, we continue advocating the FS approach as more direct and fundamental, for assessing idealized scramjet flameholding potentials, than measurements of "unstrained" laminar burning velocity or blowout in a Perfectly Stirred Reactor.
\end{abstract}

* Senior Research Scientist, Hypersonic Air Breathing Propulsion Branch, Research and Technology Directorate. MS 168, NASA Langley Research Center, Hampton, VA 23681. Senior Member, AIAAｇ.l.pellett@larc.nasa.gov

2 NASA-Langley Virginia Governor's School Participant, Summer 2006. Student at: Staunton River High School, Moneta, VA; and The Roanoke Valley Governor's School for Science and Technology, Roanoke, VA

${ }^{3}$ Technician, Lockheed Martin Space Operations, Hampton, VA

This material is declared a work of the U.S Government and is not subject to copyright protection in the United States.

Approved for public release; distribution is unlimited. 


\section{Introduction}

For over 40 years, vaporized liquid hydrogen has been used almost exclusively in attempts to realize the potential of (airbreathing) Supersonic Combustion Ramjet (SCRAMJET) propulsion. Although liquid hydrogen is difficult and expensive to use, it has remained the "fuel of choice," largely because of gaseous hydrogen's exceptional reactivity at near-atmospheric pressures; in addition, it delivers a high specific impulse, and has a uniquely high capacity for active cooling. Vaporized liquid hydrocarbon $(\mathrm{HC})$ fuels, on the other hand, have been of limited use in hoped-for supersonic airbreathing applications, because they are far less reactive, even though they are obviously much easier to store and handle. Also, endothermic catalytic cracking of HC fuels has been investigated [1-5] to improve both reactivity and cooling capacity. However, difficult and competing performance challenges remain to achieve ignition and robust flameholdingcombustion with various fuels in relatively small subsonic cavity flameholders [4-12] - so as to (1) promote rapid initial reaction with sufficient release of radicals and (limited) heat, (2) avoid excessive internal drag and loss of net thrust, and (3) achieve needed "endothermic" heat soak and enhanced fuel reactivity in active cooling channels without the formation and deposition of significant carbon residues [3-6]. Thus thermally- or catalytically-cracked fuel vapor and entrained air must partially mix, diffuse and react long enough in a subsonic cavity to achieve ignition with robust "incipient flameholding," so as to supply adequate radicals and enthalpy to the overriding supersonic flow, with minimal loss of kinetic energy.

Opposed Jet Burner (OJB) tools have been used extensively by the authors to measure the extinction limits of numerous laminar non-premixed fuel-air Counterflow Diffusion Flames (CFDFs) at one atmosphere [19-30]. Early efforts focused on: The velocity [29] and thermal structure $[21,28]$, and strain-induced extinction of 14 to $100 \%$ hydrogen-air CFDFs, summarized in [19]; the efficacy of silane/hydrogen and silane/hydrocarbon mixtures for piloting (without extinction) very high speed combustion $[20,26]$; and the effects of contaminants in vitiated air from test facilities on $\mathrm{H}_{2}$-air extinction limits [22-25,27]. The latter effects have been reviewed and used to assess possible differences in "incipient flameholding," compared to clean air in flight, in the subsonic re-circulating flows of an otherwise supersonic combustor [31,32]. The CFDF studies showed that Flame Strength, FS, defined locally as the laminar maximum average air input velocity, $U_{\text {air }}$, that sustains combustion of a particular counterflowing jet of gaseous fuel just before extinction, represents a unique and important fuel and air characterization parameter for chemical-kinetic-controlled extinction; and the FS limits effectively apply to "idealized" scramjet flameholding [19,31,32]. Thus measurements of Applied Stress Rate (ASR) at extinction, defined as $U_{\text {air }}$ normalized by either nozzle or tube diameter, $D_{\mathrm{n}}$ or $\mathrm{t}$, can be compared directly with numerically simulated laminar extinction limits $[28,29,19,33]$. Such limits may be evaluated with reasonable accuracy using either a 1-D Navier Stokes stream-function approximation [see 19,30] with detailed transport and finite rate chemistry, or with much greater accuracy using a fully detailed 2-D Navier Stokes numerical simulation [33].

\section{Previous OJB Characterizations that Underlie Present Work}

In [36], which followed earlier work [34,35], we presented some key experimental and analytic results that help define the combustion and extinction of gaseous HC-air CFDFs. Since then, refined interpretations of the [36] results, and also newly plotted results, have been introduced to further support the OJB methodology. Because some of these results are especially relevant to the current work, they are detailed in Appendix A, entitled "Supporting Strain Rate Characterizations," and some key features are summarized below:

(1) A plot (see Fig. A1) of Laser Doppler Anemometry (LDA) data for opposed cold flows of air from large contoured nozzles $\left(D_{n}=25 \mathrm{~mm}\right.$ diameter) [44] illustrates that relatively close nozzle separations significantly affect measured axial and radial strain rates at fixed exit flow rates, and also certain strain rate approximations used by other researchers. An expression 
defined first in [46] for large diameter matrix type OJBs, and then employed in several later studies (including extinction of $n$-heptane-air flames), departs significantly $(\sim 2.4 \mathrm{x}$ high) from a small extrapolation of measured strain rates when the nozzles are very closely spaced $\left(H / D_{\mathrm{n}} \sim 0.45\right)$. However, a very early expression [45], $U_{\text {air }} / D_{\mathrm{n}}$, is only about $10 \%$ low of the (1) Ref. [44] measured radial and $-1 / 2$ axial strain rates for $H / D_{\mathrm{n}} \geq 1$, and also (2) 2-D numerically simulated strain rates [33].

(2) The author's previous extensive ASR extinction results, for $\mathrm{N}_{2}$-diluted $\mathrm{H}_{2}$ vs air using tubeOJBs with parabolic inflows [19] $\left(\mathrm{ASR}_{\mathrm{t}}=U_{\text {air }} / D_{\mathrm{t}}\right)$, were well characterized (Fig. A6) for wideranging tube diameters $(1.8-10 \mathrm{~mm})$ and $\mathrm{H}_{2}$ concentrations $(20-100 \%)$. However, quite recently, these $\mathrm{H}_{2} / \mathrm{N}_{2}$-air ASR extinction data were found to differ systematically from the entire set of $\mathrm{HC}$-air ASR data, when compared with ASR data from nozzle-OJBs with plug inflows (Fig. A7). This primarily reflects a significant relative difference in diffusion rates, and consequently, the location of the flame zone with respect to the stagnation point (greater for $\mathrm{H}_{2}$ ), where differences in the divergence of the air jet (tube-OJB) alter the local radial strain rate that effectively controls extinction [33].

(3) Two plots of extinction ASRs (Figs. A2 and A3) for all five of the simple gaseous HC-air systems studied, and nearly all the OJB tube sizes used (7 sets, $2.7-10 \mathrm{~mm})$, illustrated asymptotic approaches towards effectively constant ASR limits for each fuel as tube diameter increased (relative to flame thickness), and as exit Reynolds number increased.

(4) A series of $\mathrm{HC}$-air extinction results for $\mathrm{N}_{2}$-diluted ethylene vs air (Fig. A4), from a "flowfield-standardized" contoured-Pyrex nozzle-OJB $(7.2 \mathrm{~mm})$, characterized a three-fold increase in $\mathrm{FS}$ as $\mathrm{N}_{2}$ dilution diminished from $80 \%$ to $20 \%$, and was followed by an asymptotic approach to steady state $\mathrm{FS}$ for pure $\mathrm{C}_{2} \mathrm{H}_{4}$. Also, the same system was used to characterize the dynamic response of five gaseous $\mathrm{HC}$-air systems [37-40], in which steady plus oscillatory velocity inputs caused unique and systematically decreasing extents of Dynamic Flame Weakening (for each fuel), at frequencies from 8 to $200 \mathrm{~Hz}$. Notably, from 300 to $1600 \mathrm{~Hz}$ (limit of the study), weakening due to lagging diffusion response of the flame was negligible, as flames became totally insensitive to oscillatory inputs. Similar (proportional) Dynamic Flame Weakening effects should be expected for tube OJBs.

(5) Notably, extinction limits for all the $\mathrm{N}_{2}$-diluted $\mathrm{H}_{2}$ and $\mathrm{HC}$ systems investigated showed asymptotic approaches to nearly constant FSs as pure fuel was approached. Thus extinction limits were essentially unaffected by increasing fuel diffusion rates to the (generally) airside flames, and hence extinctions were controlled primarily by chemical kinetic rates.

(6) The collective extinction results for gaseous HCs were illustrated on a so-called "Idealized Flameholding Scale," consisting of $\mathrm{ASR}_{\mathrm{n}}$ from nozzle-OJBs plotted versus $\mathrm{ASR}_{\mathrm{t}}$ from tubeOJBs. This scaling approach illustrated (updated later in Fig. 6) the relatively large effect (2.5 $\mathrm{x}$ ) of differing axial velocity inflow profiles (plug vs parabolic) on ASRs for the various HC fuels, while exhibiting mutual linear proportionality to wide-ranging fuel oxidation rates.

(7) The FSs of $\mathrm{N}_{2}$-diluted vaporized $n$-heptane and JP-7 mixtures vs air (Fig. A5) also exhibited the same kinetically limited (asymptotic) response as did the normally gaseous HCs. In addition, the $n$-heptane data compared favorably with published extinction results (available up to a 26 mole \% limit) when the published data, obtained at relatively small gaps, were appropriately corrected [36], based on Rolon's LDA strain rate characterizations [44].

(8) A series of four figures illustrated the strong negative effects on FSs of using methane, propane, and ethylene $\mathrm{HCs}$ to dilute $\mathrm{H}_{2}$ (and "scavenge" $\mathrm{H}$-atoms), compared to the negligible effects of $\mathrm{N}_{2}$ dilution on $\mathrm{FSs}$ at high $\mathrm{H}_{2}$ concentrations (say, $80 \%-100 \%$ ). These plots also showed essentially negligible effects on $\mathrm{FS}$ of $\mathrm{H}_{2}$ addition to $\mathrm{HCs}$ at low $\mathrm{H}_{2}$ concentrations (say, $0-20 \%$ ). 
(9) The comprehensive "Idealized Flameholding Scale" (updated later in Fig. 7), that included most of the various ASR results discussed above, showed a factor of 50 applied for pure $\mathrm{H}_{2}$ compared to pure JP-10, and clearly illustrated that reactions of $\mathrm{HCs}$ (most likely) with $\mathrm{H}$ atoms in mixed $\mathrm{H}_{2}+\mathrm{HC}$ systems produced large decreases in flame strength.

In summary, [36] provided extensive fundamental OJB extinction data and analyses that helped better define the effects of input temperature, barometric pressure and jet diameter, and inflow Reynolds number and velocity profile (plug vs parabolic inflows) on FSs and ASRs, for the global testing of detailed chemical kinetic models for $\mathrm{HC}$ fuels. It also produced a refined characterization of "idealized flameholding potentials" that apply over a very wide-ranging scale of limiting fuel reactivity (extinction) caused by highly strained aerodynamic flows under well-defined conditions. Thus the FS and ASR approach to the assessment of "incipient" flameholding limits in practical $\mathrm{HC}$-air systems at $\sim 1 \mathrm{~atm}$ was devised as a useful and convenient basis for assessing the loss of non-premixed idealized, incipient flameholding in more complex scramjet combustors.

Finally, although [36] included FS results for six single-component hydrocarbon (HC) fuels, their nitrogen-diluted counterparts, and three $\mathrm{HC}$-diluted $\mathrm{H}_{2}$ fuels that showed very nonlinear decays in FS as $\mathrm{HC}$ was added, no binary mixtures of simple HCs were studied to identify possible nonlinear interactions. Thus, in the face of increasing interest in $\mathrm{HCs}$, both pure and mixed, and especially ethylene due to its high FS reactivity (and apparent potential as a scramjet fuel component - described below), we considered it important to explore wide-ranging mixtures of various $\mathrm{HCs}$ with ethylene -- which may behave nonlinearly (due, e.g., to $\mathrm{H}$-atom playing a significant role).

\section{New Results in the Present Paper}

This paper presents new and comprehensive Flame Strength results on six mixed HC systems. These include four binary gaseous HC systems and two ternary vaporized HC systems. The binary systems consist of methane + ethylene, ethane + ethylene, methane + ethane, and methane + propylene. The ternary systems include both 10.8 and 21.3 mole $\%$ vaporized $n$ heptane (a "gold standard" among liquid fuels) and respective full ranges of methane + ethylene variation. Four major purposes are served: (1) The normalized data from these $\mathrm{HC}$ mixtures provide sensitive and accurate means of validating, globally, complete (and reduced) chemical kinetic mechanisms at the peak (flame core) temperatures corresponding to non-premixed flame extinction, and at the moderately elevated fuel inflow temperatures used in several cases; (2) The experimental FS and ASR scaling, in combination with refined and appropriately validated reduced kinetic mechanisms, may be used to help assess (approximate) the loss of "incipient" flameholding in scramjet combustors when both pure and mixed HC fuels are used; (3) The results provide direct means of defining simple (e.g., binary) gaseous surrogate fuel mixtures that accurately mimic the flame strength of more complex mixtures. Such surrogates may allow substitutional bypassing of complex vaporization and catalytic cracking systems when scramjet combustion operability is the major goal. Also, surrogate mixtures may offer important additional test flexibility and research value by allowing a straightforward and well-defined means of systematically varying fuel reactivity, as a means of mapping the limits of robust and weak flameholding; and (4), perhaps most importantly, this paper focuses particularly on defining simple gaseous surrogate fuel mixtures that can mimic the flameholding behavior of an endothermically cracked JP-7 "like" kerosene fuel. More specifically, in addition to the fact that $n$ heptane is a "gold standard" of liquid HC fuels, it is also the minor component of a surrogate fuel that has been proposed [6] to mimic the ignition behavior of an endothermically cracked JP "like" kerosene fuel. The composition of a suitable "baseline simulant" (10 mole \% $n$-heptane, 30\% methane, $60 \%$ ethylene) was deduced and recommended by Colket and Spadaccini, based partly on detailed experimental shock tube data in their "Scramjet Fuels Autoignition Study" [6]. Thus, consistent with our proposed use of FS to gauge idealized scramjet flameholding limits, we focus particularly on characterizing FSs of the entire $n$-heptane + methane + ethylene system; and comparable FSs of the ternary ethane + methane + ethylene system, the binary methane + ethylene system (preferred candidate for high pressure storage), and the binary ethane + 
ethylene system (which has nearly constant molecular weight), as surrogate candidates for mimicking the "essential" flameholding behavior of an endothermic catalytically-cracked JP-7 "like" fuel.

\section{Experimental}

Schematics, with detailed descriptions, are given for the nozzle-OJB system used (vertical orientation with a passive Oscillatory-inflow delivery), Fig. 1a; a recent horizontal tube-OJB system, Fig. 1b; and the liquid $\mathrm{HC}$ vaporizer-accumulator-OJB system, Fig. 1c. All three systems depict the use of convergent Pyrex nozzles, and long nickel or stainless steel tubes (50 to 100 diameters), of the same size and type. No guard flows were used (or seemed to be needed) at the typical flow rates employed for extinction of thin disk-shaped flames. Although horizontal configurations sometimes show a slight flame asymmetry due to buoyancy (but negligible differences in results) [26], they favor formation of resultant ring-shaped flames, and thus allow measurements of flame restoration, which approximate a slightly strained laminar burning velocity (discussed below). Each ceramic fiberboard combustion box had Pyrex windows, and a porous sintered metal plate over the top. Nitrogen (or argon) entering through diffuser-jets at the bottom of each box reduced extraneous combustion outside the central impingement region, and thus minimized adverse buoyancy and visibility effects. Fuel and air component flows were handcontrolled with micrometer valves, and measured by mass flow meters calibrated for air at $0^{\circ} \mathrm{C}$ and $1 \mathrm{~atm}$. Vendor-published mass flow meter correction factors (either measured relative to air or evaluated as ratios of heat capacities) were used for calculating mole fractions of HC mixtures involving ethane, propane, butane and propylene. Similar published factors for methane and ethylene were found in significant error, and were thus evaluated independently in a series of carefully controlled experiments (discussed later).

To attain extinction (blowoff) of a stabilized gaseous fuel-air disk flame, the fuel flow rate was gradually increased (or, for $\mathrm{N}_{2}$ diluted fuels, fixed at a target rate as $\mathrm{N}_{2}$ diluent was increased); simultaneously, the airflow was gradually increased, so the flame was always centered and freefloating (fully responsive to small differential changes in flow rates). Upon sudden blowoff, a ringshaped (torus) flame sometimes stabilized. After mass flows of each component were recorded, gradual flow reductions led to slow closure of the ring flame, and eventually, to sudden disk restoration (see [19] for a summary of the author's earlier CFDF restore results, and [50] for a very recent detailed study). Extinction data were almost always obtained in duplicate, and were sometimes replicated 10 or more times, especially in the case of heated / vaporized liquid fuels. Here, premixed (with $\mathrm{N}_{2}$, or one or two gaseous $\mathrm{HCs}$ ) vaporized-HC flows from the pressurized accumulator system, Fig. 1c, were simply varied in tandem with flows of air to achieve extinction. Similar procedures applied for mixed gaseous $\mathrm{H}_{2} / \mathrm{HC}$-air and $\mathrm{HC}_{1} / \mathrm{HC}_{2}$-air systems, in that $\mathrm{H}_{2}$ or one $\mathrm{HC}$ diluent / reactant was fixed while the other was gradually increased in tandem with air to achieve extinction.

Reported exit cross-section-average jet velocities, $U_{\text {air }}$ and $U_{\text {fuel }}$, are calculated from measured component mass flow rates, flow meter calibration factors for each gas, and carefully measured nozzle or tube exit diameters. Mass flow meter calibrations of airflow rates are referenced to $0^{\circ} \mathrm{C}$ and 1 -atm, but are then corrected to $300 \mathrm{~K}$ (ideal gas law) and 1-atm [36]. Corresponding $R e_{\text {air }}$ based on diameter were generally less than 1500 , but considerably lower values were avoided; especially because flames can become excessively thick when vertical, and also non-axisymmetric when horizontal, due to buoyancy. Radiation effects were considered negligible at the relatively high strain rates used.

The matched tube-OJBs $(7.56 \mathrm{~mm}$ diameter mostly, but ranging 2.7 to $10.0 \mathrm{~mm}$ in previous studies) were mounted horizontally. The $7.2 \mathrm{~mm}$ Pyrex nozzles were mounted vertically, with both elements insulated to reduce heating of the inflowing gases. 
The $7.5 \mathrm{~mm}$ tube- and $7.2 \mathrm{~mm}$ nozzle-OJBs were spaced 1.7 to 2 exit-diameters apart (note, the extinction limits are exceptionally independent of jet separation distance beyond one diameter, and sometimes up to 4 diameters [19]). For measurements with $\mathrm{H}_{2}$, both the 2.7 and $2.91 \mathrm{~mm}$ OJB's were $7 \mathrm{~mm}$ apart to ensure free-floating finite-thickness flames, free of significant flame attachment / anchoring effects. Flow rates were generally high enough that buoyancy and OJB orientation effects on flame extinction appeared negligible $[19,36]$ whenever data were recorded. Vaporized-HC fuel mixtures flowed through the electrically heated vaporizer and accumulator tanks and tubes with thermocouple monitoring (see Fig. 1c), before entering the OJB combustion chamber, so these fuels were heated up to $\sim 600 \mathrm{~K}$ to prevent condensation.

Several checks were also made on possible temperature-time degradation effects on HCs. The checks included propane-air ASR extinction limits, using $300 \mathrm{~K}$ air and unheated propane $(101.41 / \mathrm{s}$ at $300 \mathrm{~K})$; rapidly heated propane $(105.21 / \mathrm{s}$ for $\leq 0.1 \mathrm{hr}$ at $600 \mathrm{~K})$, and long-termheated propane (104.4 1/s for $\sim 2 \mathrm{hr}$ at $600 \mathrm{~K}$ ). These results show a small increase in ASR due to heating $(3.8 \%$ ave $)$, and a negligible difference $(\sim 1.5 \%)$ that might be ascribed to possible decomposition effects (short- vs long-term "cooking") [36]. Similar checks on possible degradation were conducted on both ethylene and methane, with similar results (described later).

Errors in extinction limits stemmed from various sources. In earlier studies of the $\mathrm{H}_{2}$-air system, absolute strain rates at extinction (not density weighted) were predicted (1-D) to vary linearly with input temperature, up to $\sim 600 \mathrm{~K}[41,42]$, and absolute ASRs for heated $\mathrm{H}_{2}$-air, using a $2.7 \mathrm{~mm}$ tube-OJB, were found to vary "nearly" linearly (e.g., with only a $14 \%$ excess increase in density-weighted ASR from 300 to $600 \mathrm{~K}$ [43]). Thus direct measurements of mass flow rates effectively negated most effects of variable jet temperature on absolute jet velocity, via the ideal gas law. This led to significant reduction of data scatter, especially when input heating was required. Atmospheric pressure variations caused small variations of $U_{\text {air }}$ extinction limits that were generally ignored and averaged-out during earlier hydrogen studies [19], but more recent $\mathrm{HC}$ and $\mathrm{H}_{2}$ data were corrected [36] by applying a dimensionless pressure ratio of $(1 / P)^{+3}$. Calculated (density-weighted) jet exit velocities at standard conditions varied inversely as the square of measured $D$, and ASRs varied as $D^{-3}$. Finally, un-reconciled small differences between data sets were due to earlier unmeasured variations in atmospheric pressure; differences in centering flames; daily jet realignment; sporadic but generally small mass flow meter drift; periodic mass flow meter calibrations; small transient cooling / heating flow response effects in flow meters; and differences in the spatial distribution and flow rates of argon or nitrogen purge flows in the combustion box.

Finally, because jet-edge velocity-mismatch and resultant bath gas entrainment / diffusion effects were incipient and evident at high $\mathrm{H}_{2}$ concentrations with the $2.7 \mathrm{~mm}$ nozzle-OJB [19], and also the flame thickness at extinction was as large as $\sim 1 / 3 D$, the greatest uncertainty and nonideality in our previous $\mathrm{H}_{2}$-"clean air" extinction studies [19] is now believed to be associated with the $2.7 \mathrm{~mm}$ Pyrex nozzle-OJB. On the other hand, the 2.7 and $2.9 \mathrm{~mm}$ tube-OJBs performed much more ideally due to the lack of significant "velocity-mismatch" at each jet's edge.

In summary, a relatively ideal and well characterized $7.56 \mathrm{~mm}$ tube-OJB (and $7.2 \mathrm{~mm}$ nozzleOJB) were the primary tools used for assessing strain-induced extinction limits of gaseous and vaporized-liquid $\mathrm{HC}$-air CFDFs in the present study.

\section{Results and Discussion}

\section{OJB-Extinction "Flameholding Scale" for Pure and Mixed Gaseous HCs}

Fig. 2 shows newly acquired Applied Stress Rate (ASR) data at extinction, for binary

methane + ethylene fuel mixtures vs air, using a $7.56 \mathrm{~mm}$ Tube-OJB at $1 \mathrm{~atm}$, with $300 \mathrm{~K}$ inputs. 
Flame extinction occurred at each data point, and thus the data fit marks an ASR boundary beyond which flame cannot exist. The depicted ethylene mole fractions in the fuel were calculated using newly evaluated mass flowmeter correction factors, derived from more than twodozen independent flow measurements. The relatively mild nonlinearity in Fig. 2 is reminiscent of much larger nonlinearities seen earlier [36] in the $\mathrm{HC}+\mathrm{H}_{2}$ systems, in that it may also reflect a degree of scavenging of $\mathrm{H}$-atoms from ethylene decomposition by $\mathrm{HCs}$ stemming from methane.

More concrete chemical explanations of the system response must await the application of refined global chemical kinetic formulations, in which detailed sensitivity and reaction path analyses, followed by numerical simulations of OJB extinction, attempt to match pure-HC ASRs (and eventually their nonlinear trends with mole fraction), as recently reported for methane-air and ethylene-air in [51]. Such considerations also apply in far more complex fuel systems, in which the detailed chemical kinetics are sometimes extremely complicated [13-18], and where kinetics and diffusion often play critical and competing roles [17,18].

Fig. 3 shows comparable ASR data for the ethane + ethylene system, which exhibits an even milder nonlinearity with mole fraction ethylene. Notably, ethane has a higher FS than methane; a lower vapor pressure at ambient temperature; and approximately the same molecular weight as ethylene (30 vs 28 ). All three of these properties may conceivably be important in selecting a binary gaseous surrogate-FS composition.

Fig. 4 shows ASR data for the methane + ethane system, which exhibits highly linear behavior with mole fraction ethane. This suggests the flameholding-combustion of each (similar) $\mathrm{HC}$ proceeds as if the $\mathrm{HCs}$ behave independently, and in proportion to their molecular abundance. However, it remains to be confirmed through detailed 1-D CFDF numerical modeling whether this linearity, or the nonlinearities shown in Figs. 2 and 3 for mixtures with "highly reactive" ethylene, can be rationalized.

Note the above three systems in Figs. 2 through 4 constitute a simple ternary system that can be completely characterized, analytically, without the need for additional ternary-mapping data if a relatively simple and reasonable assumption is made. That is, the linearity in Fig. 4 (for zero ethylene) is also assumed to hold for all sets of mixtures in which ethylene mole fraction is constant. Thus an analytic surface can be (and has been) constructed consisting of an infinite number of straight lines that connect the respective parabolic fits of methane + ethylene, and the ethane + ethylene systems, on lines of constant ethylene mole fraction.

Fig. 5 shows ASR data for the methane + propylene system, which also exhibits highly linear behavior with mole fraction propylene. These data are somewhat surprising in two respects. First, the ASR for $300 \mathrm{~K}$ propylene-air at extinction (107 1/s) is about $2 x$ lower compared to $300 \mathrm{~K}$ ethylene (212 1/s); and second, the mixed fuel system behaves linearly with mole fraction.

Fig. 6 adds a new gas to the earlier correlation [36] for all the pure gaseous $\mathrm{HCs}$ at $300 \mathrm{~K}$, and shows resultant OJB-extinction-limits for six HCs on a linear, "Idealized Flameholding Scale." These ASRs were obtained using the $7.2 \mathrm{~mm}$ convergent Pyrex nozzle-OJB and a $7.5 \mathrm{~mm}$ straight tube-OJB (except for two sets of methane-air data from a $5.1 \mathrm{~mm}$ Pyrex nozzle and a 5.0 $\mathrm{mm}$ tube). Note many of the results (including ethylene) stem from averaged multiple-entry determinations. Also, care was taken that both nozzle and tube data were taken at approximately the same time, to minimize effects of air mass flowmeter drift; note, for example, the tube (and nozzle) data for the ethane point are slightly lower than tube data obtained a year later, as shown in Figs 3 and 4. Ethylene exhibits by far the highest Flame Strength (ASR) of any HC tested.

Finally, note the highly linear correlation of averaged data in Fig. 6 that shows ASR(nozzle, $\mathrm{w} /$ plug inflow) $=2.51 \mathrm{ASR}$ (tube, w/parabolic inflow). The same ratio (2.5) coincides nearly exactly with: (1) respective axial and radial SR ratios, for parabolic / plug profiles with identical cold mass inflows, from a 2-D numerical simulation [33]; (2) axial parabolic / plug SR ratios derived for extinctions of $\mathrm{H}_{2}$-air CFDFs, using the same 2-D numerical simulation [33]; and (3) a recently revised analysis [GLP manuscript in preparation] of earlier LDV and PIV measurements $[29,19]$ of 
respective axial strain rates, for equal (cross-section-average) $U_{\text {air }}$ inflows just upstream of $\mathrm{H}_{2} / \mathrm{N}_{2}$-air CFDFs, using respective $7.5 \mathrm{~mm}$ tube- and $7.2 \mathrm{~mm}$ nozzle-OJBs. In conclusion, the measured ratio (2.5) of respective OJB nozzle- vs tube-derived ASRs for gaseous HCs is entirely consistent with both numerically-derived and measured SR ratios.

\section{Comprehensive "Idealized Flameholding Scale" for $\mathrm{HCs}, \mathrm{H}_{2}$ and Mixtures}

Fig. 7 now extends the linear "Idealized Flameholding Scale" of Fig. 6, by summarizing extinction ASRs for all the pure gases (but no mixtures), some $\mathrm{N}_{2}$-diluted $\mathrm{HC}$ fuels, and the previously discussed $\mathrm{H}_{2}$-air, and $\mathrm{H}_{2} / \mathrm{HC}$-air systems, where the ASRs represent respective FSs normalized by nozzle or tube diameter, $D_{\mathrm{n}}$ or t. The three sets of pure- and nitrogen-diluted vaporized-HC FS data from Fig. A5, for 100\% JP-10-air, and both pure and nitrogen-diluted JP-7 and $n$-heptane vs air, were obtained in [34,35], and the mole fractions for $\mathrm{N}_{2}$-diluted mixtures were slightly revised in [36].

Thus, Fig. 7 shows a 50-fold range of normalized ASR's for various "pure" vaporized-liquid and gaseous hydrocarbons, including, in ascending order: JP-10, methane, JP-7, $n$-heptane, $n$ butane, propane, propylene, ethane, and ethylene. Pure hydrogen produces a unique and exceptionally strong flame at the extreme upper end of the flameholding scale (see also Fig. A6). Both $\mathrm{H}_{2}$ data points (averaged from previous $2.7 \mathrm{~mm}$ Pyrex nozzle- and $2.7 \mathrm{~mm}$ tube-OJB data, and also obtained from a recent $2.91 \mathrm{~mm}$ tube-OJB) agree within about $1 \%$ of Hwang's recent 2D numerically simulated ASRs for $\mathrm{H}_{2}$-air extinction, for a $3 \mathrm{~mm}$ tube-OJB configuration with appropriate guard flows and disk-shaped boundary conditions [33]. For all the data points marked with a pound sign (\#), measurements made with tube-OJBs were plotted on a leastsquares fit of all the gaseous $\mathrm{HC}$ data and the data for pure $\mathrm{H}_{2}$ described above. Although the linear slope increased from 2.51 to 2.73 due to addition of pure $\mathrm{H}_{2}$ data, the former slope (2.51) is now considered most appropriate for HC CFDFs. This is primarily due to the newly-recognized effect of a downstream shift in the average $\mathrm{HC}$ flame location, on the airside, relative to that for hydrogen, as described earlier.

Based on the above FS and ASR characterizations, including the $50 \times$ range of linear reactivity between JP-10 and $\mathrm{H}_{2}$ exhibited on the (logarithmic) "Idealized" flameholding scale of Fig. 7, we reiterate the conclusion of [36] that respective nozzle- and tube-inflow experimental ASRs, and ratios of ASRs for various "pure" hydrocarbons and hydrogen, effectively represent global chemical kinetic limits. And, as such, the ASRs provide absolute and relative tests of the validity of reduced chemical kinetic models, when applied at the appropriate pressures (and consequent peak flame core temperatures) of extinction.

\section{Extinction Results for Hot $(600 \mathrm{~K})$ Ternary Methane + Ethylene + $\boldsymbol{n}$-Heptane Mixtures}

Fig. 8 shows a "higher fuel temperature" version of the Fig. 2 ASR data at extinction, for binary methane + ethylene fuel mixtures vs air, using a $7.56 \mathrm{~mm}$ Tube-OJB at $1 \mathrm{~atm}$, with $300 \mathrm{~K}$ air inputs and fuel inputs at $\geq 600 \mathrm{~K}$. This "hot" version was obtained after both pure methane and pure ethylene charges were heated to $\geq 600 \mathrm{~K}$ for $\geq 1 \mathrm{hr}$, at $\sim 70$ psia, to obtain high temperature ASR data at each extreme (described below). Then, the Fig. 2 data were temperature-corrected by applying resultant linear (interpolated) factors to the ASR results at intermediate mole fractions.

The high temperature extinction measurements for both methane and ethylene were obtained after the respective fuels were heated to $\geq 600 \mathrm{~K}$ for $\geq 1 \mathrm{hr}$, to obtain "cooked fuel" ASRs at the same elevated temperatures used to vaporize liquid fuels. Subsequently, additional experiments were conducted to directly assess possible thermal and HC-decomposition effects on ASRs. Thus repetitive FS measurements were obtained from "cooked" fuel (designated $\geq 1.0 \mathrm{hr}$ at $\geq 600$ $\mathrm{K}$ ), as the $10.6 \mathrm{~L}$ hot vaporizer-accumulator system was brought down from $\sim 70 \overline{\mathrm{p}}$ sia to $\sim 1 \overline{5}$ psia. Then, fresh gaseous fuel was introduced to the hot system to raise the pressure back to 30 psig, and fresh fuel flow was maintained while a second repetitive series of extinction 
measurements was obtained, designated $\sim 0.1 \mathrm{hr}$ at $\geq 600 \mathrm{~K}$. Finally, e.g. the next day, "cold 300 $\mathrm{K}$ fuel" was used to produce an independent $300 \mathrm{~K}$ baseline that could be compared with the hot measurements. Thus respective averages were determined for "cooked," "rapidly-heated," and "cold" fuels to assess the respective absolute and relative effects on FS and ASR.

The respective ASRs (1/s) obtained for methane are: $80.9 \pm 0.6$ for $\geq 1 \mathrm{hr}$ at $630 \mathrm{~K} ; \mathbf{8 1 . 0} \pm$ $0.6 \mathrm{for} \simeq 0.1 \mathrm{hr}$ at $630 \mathrm{~K}$; and $80.4 \pm 0.4$ at $300 \mathrm{~K}$. (Bold notation is used to highlight the main results.) These ASRs show a negligible effect of both temperature and heating time in our system, which is characterized by a very low average surface to volume ratio, compared to flow in typical small tubes. In fact, the results closely resemble the previously discussed results for propane [34,35] that were: $\mathbf{1 0 4 . 4} \pm 1.1 \mathrm{for} \geq 1 \mathrm{hr}$ at $600 \mathrm{~K} ; \mathbf{1 0 5 . 2} \pm 0.4 \mathrm{for} \simeq 0.1 \mathrm{hr}$ at $600 \mathrm{~K}$; and 101.4 at $300 \mathrm{~K}$. Finally, the respective ASRs (1/s) for ethylene are: $228.4 \pm 1.5$ for $\geq 1 \mathrm{hr}$ at 620 $\mathrm{K} ; 226.1 \pm 0.7 \mathrm{for} \simeq 0.1 \mathrm{hr}$ at $640 \mathrm{~K}$; and $211.3 \pm 5.9$ at $300 \mathrm{~K}$. These show negligible difference between cooked and rapidly heated ethylene, but together they average about $7.5 \%$ higher than for cold ethylene. As indicated earlier, the above "hot" ASRs for methane and ethylene were used to correct the cold ASR data in Fig. 2 to hot ASRs in Fig. 8.

Fig. 9 shows ASRs at extinction for $\sim 600 \mathrm{~K}$ ternary mixtures of $\mathbf{1 0 . 8} \pm \mathbf{0 . 3}$ mole $\% \boldsymbol{n}$ heptane + methane + ethylene vs $300 \mathrm{~K}$ air. Note the datum point that characterizes an ASR corresponding to Colket and Spadaccini's simulated endothermically-cracked JP-7 "like" kerosene, as derived from their shock tube ignition studies at 6-8 atm [6]. The degree of nonlinearity observed in Fig. 9 is very similar to that in Fig. 8, but it has a larger ASR intercept for $90 \%$ methane, and a lower ASR intercept for $90 \%$ ethylene. Both findings are consistent with the ASR for pure $n$-heptane in Fig. A5 and Fig. 7, and relative ASRs for pure methane and ethylene. However, careful chemical kinetic modeling is clearly needed on the ternary system, once the binary gaseous system has been successfully characterized.

Fig. 10 shows ASRs at extinction for similarly hot ternary mixtures of $\mathbf{2 1 . 3} \pm \mathbf{0 . 5}$ mole $\% \boldsymbol{n}$ heptane + methane + ethylene vs $300 \mathrm{~K}$ air. The data trends are an unremarkable extension of Figs. 8 and 9, but they enable a more comprehensive and accurate fit of the ternary system.

Fig. 11 shows ASRs at extinction for hot binary mixtures of $\boldsymbol{n}$-heptane + ethylene vs $300 \mathrm{~K}$ air. The data fit provides a zero-methane baseline for the hot ternary system. Note the results from three different tests (described above) for pure ethylene, used to assess possible thermal and ethylene-decomposition effects on ASR at elevated fuel input temperatures ( $630 \mathrm{~K})$.

Fig. 12 shows ASRs at extinction for hot binary mixtures of $+\boldsymbol{n}$-heptane + methane vs $300 \mathrm{~K}$ air, which provides a zero-ethylene baseline for the hot ternary system. Although these data are less extensive at intermediate concentrations, the ASR difference spanned is not great. Note the results from three different tests (described above) for pure methane, to assess possible thermal and methane-decomposition effects on ASR at elevated fuel input temperatures $(\sim 630 \mathrm{~K})$.

\section{Fits of Hot Methane + Ethylene $+n$-Heptane System, and Definition of Surrogate Fuels}

The above five sets of ASR extinction data in Figs. 8-12, that apply to the hot $(600 \mathrm{~K})$ ternary system of methane + ethylene $+n$-heptane, are now analyzed to produce (four slightly different) analytic polynomial fits that apply (sometimes with extrapolation) over the entire range of fuel compositions. Thus, respective ASRs are first calculated that correspond to the Colket and Spadaccini "reformed fuel" or "baseline simulant" composition (10 mole \% $n$-heptane with $30 \%$ methane $+60 \%$ ethylene) that was proposed [6] to "mimic" the ignition behavior of endothermically cracked JP-7 "like" kerosene fuel. Then, respective ASRs for the above ternary system are used to deduce the composition of hot binary methane + ethylene surrogates that exhibit identical ASRs in each case, as follows. 
First, for the most inclusive "basic" fit, the three "boundary" sub-systems in Figs. 8, 11, and 12 are used to generate an ASR surface. These bound the basic ternary system to be characterized analytically (as before, e.g.,with methane + ethylene + ethane), without the need for additional ternary-mapping data if a relatively simple and reasonable assumption is made. That is, the effective linearity in Fig. 12 (for zero ethylene) is also assumed to apply for all possible sets of mixtures in which ethylene mole fraction is constant. Thus a continuous surface is generated consisting of an infinite number of straight lines that connect respective parabolic fits of the hot methane + ethylene and the hot $n$-heptane + ethylene systems, along lines of constant ethylene mole fraction.

The "first" analytic surface solution was bounded by parabolic fits of data in which $n$-heptane mole fraction, $X(H)$, varied between 0 \& 1.0. A second surface was similarly derived, but was bounded by $X(H)$ between $0.108 \& 1.00$. A third surface was bounded by $X(H)$ between 0.108 \& $\mathbf{0 . 2 1 3}$, and a fourth was bounded by $X(H)$ between $0 \& 0.213$. Next, respective analytic fits of the bounded ASR data were solved to deduce ASRs corresponding to the Colket and Spadaccini "baseline simulant" composition (10 mole $\% n$-heptane with $30 \%$ methane $+60 \%$ ethylene). Finally, equivalent ethylene mole fractions were calculated for each ASR to represent binary hot mixtures of methane + ethylene that exhibit ASRs identical to calculated ASRs for the ternary system.

The calculated ASRs for the hot ternary system are summarized in Table 1, under Cases 1-4, along with respective calculated ethylene mole fractions for equivalent binary hot mixtures of methane + ethylene.

Table 1. Calculated equivalent binary surrogate compositions for hot methane + ethylene mixtures. (The binary mixtures yield identical ASRs compared to ternary mixtures of 10 mole $\% n$ heptane $+30 \%$ methane $+60 \%$ ethylene, Colket and Spadaccini's proposed "baseline simulant" [6]. Results were deduced from least-squares analytic fits of differently bounded "slices" of ASR data.)

Case Number:

Calc. ASR for hot 60 mole $\% \mathrm{C}_{2} \mathrm{H}_{4}+$ $30 \% \mathrm{CH}_{4}+10 \% n$-Heptane, $1 / \mathrm{s}$

Calc. $\mathrm{C}_{2} \mathrm{H}_{4}$ mole fraction for equivalent hot $\mathrm{CH}_{4}+\mathrm{C}_{2} \mathrm{H}_{4}$ mix

Respective parabolic fits used; bounded (defined) by average $n$-Heptane mole fraction limits of:
1

154.03

0.6026

$0 \& 1.00$
2

159.89

0.6383

0.6400

160.18

153.00

0.6024

Notably, the respective solutions bounded on the left by zero $n$-heptane (Cases 1 and 4 ) produce nearly the same results, regardless of the right $n$-heptane boundary used (1.00 or 0.213$)$. However, because the desired fuel surrogate composition that best mimics the ASR of a $10.00 \%$ $n$-heptane mixture is so close to the data set for $10.80 \% n$-heptane ( 8 points), and lies just to the left of those data, Cases 2 and 3 are considered closest to a "best" recommendation of $64 \%$ ethylene $+36 \%$ methane, for an ASR of $1601 / \mathrm{s}$. A simple inspection of Figs. 9 and 8 confirms this finding. 


\section{Planned Fuel Cracking Studies Related to the Present Surrogate}

Presently, the authors are setting up an isothermal-decomposition sub-system to process (and crack) hot mixtures just before they flow to the OJB, so we can begin addressing the question "what actually is the achievable Flame Strength of a cracked JP-7?" Note, from the measured ASR = $931 / \mathrm{s}$ for "pure" JP-7, that the $1601 / \mathrm{s}$ surrogate represents a $70 \%$ increase in ASR for a "cracked" JP-7; this compares with $2271 / \mathrm{s}$ for pure ethylene (all fuels at $600 \mathrm{~K}$ ). Whether or not it is possible to gain that much Flame Strength by cracking without coking is an important question to be determined! Finally, if the $1601 / \mathrm{s}$ appears impractical, it is always possible to "ratchet down" the Flame Strength scale.

\section{Comparison of Flame Strengths with Laminar Burning Velocities}

Fig. 14 compares ASRs for the gaseous-HC extinction limits, from the $7.5 \mathrm{~mm}$ tube-OJB, with recently surveyed / published unstrained laminar burning velocity, $S_{\mathrm{L}, 0}$, measurements $[48,49]$ at an equivalence ratio of unity (phi $=1$ ). And, Fig. 15 extends the ASR results of Fig. 14 to include $100 \% \mathrm{H}_{2}$. Clearly, the ASRs reflect considerably more sensitivity to changes in fuel molecular size, type and reactivity than the $S_{\mathrm{L}, 0}$ data. In Fig. 14, a linear fit of the ASR vs $S_{\mathrm{L}, 0}$ data leads to a slope of 3.64, which appears inappropriately small for the (four lowest) saturated HCs. And in Fig. 15, a power-law fit of the gaseous- $\mathrm{HC}+\mathrm{H}_{2}$ data seems to represent the only available simple fit of the data. In this case a power-law exponent of 1.87 fits the entire data set quite well, and demonstrates a "strong apparent dependence" of ASR on a "relatively slowly changing" $S_{L, 0}$. In conclusion, unstrained laminar burning velocity changes only weakly against (highly strain-ratesensitive) Flame Strength variations. Thus burning velocity appears to be a relatively insensitive and probably unsatisfactory measure of fuel reactivity changes for use in assessing "idealized" strain-rate-sensitive flameholding at atmospheric pressure.

\section{Summary and Conclusions}

This paper presents new experimental Opposed Jet Burner (OJB) laminar Flame Strength (FS) and Applied Stress Rate (ASR) extinction results for four binary gaseous HC systems that include two ternary gaseous $\mathrm{HC}$ systems, and a multi-part ternary system with vaporized $n$ heptane. The results were obtained under idealized experimental conditions that should allow very close comparisons with the results of detailed 2-D numerical simulations, as global tests of proposed chemical kinetic models at 1-atm.

The paper first reviews and summarizes the normalization of $\mathrm{FSs}$ of $\mathrm{N}_{2}$-diluted $\mathrm{H}_{2}$ and gaseous $\mathrm{HC}$ systems to account for the effects of temperature, pressure, jet diameter, inflow Reynolds number, inflow velocity profile (plug, contoured nozzle; parabolic, straight tube) and fuel composition. Through comparisons with several earlier OJB characterizations, normalized results exemplify a sensitive accurate means of validating, globally, complete and reduced chemical kinetic models at the relatively low temperatures that govern the loss of non-premixed "idealized" flameholding at near-atmospheric pressure, e.g., in scramjet combustors.

Laminar FS is defined locally as maximum (exit) cross-section-average air input velocity, $U_{\text {air }}$, that sustains combustion of a counter flowing jet of gaseous fuel just before extinction. It uniquely characterizes a fuel combustion limit. And ASR at extinction $\left(U_{\text {air }}\right.$ at extinction normalized by nozzle or tube diameter, $D_{\mathrm{n}}$ or $\mathrm{t}$; and sometimes referred to as global strain rate) can be compared directly with computed extinction limits, determined using either a 1-D Navier Stokes streamfunction solution, using detailed transport and finite rate chemistry, or more accurately, a detailed 2-D Navier Stokes numerical simulation. 
The experimental results refine a previous "idealized flameholding reactivity scale" that shows wide ranging $(50 \mathrm{x})$ normalized-FSs (ASRs at extinction) for various vaporized-liquid and gaseous HCs, including, in ascending order: JP-10, methane, JP-7, $n$-heptane, $n$-butane, propane, propylene, ethane, and ethylene. Results from $\mathrm{H}_{2}$-air produce a unique and exceptionally strong flame that now agree within about $1 \%$ of a recent 2-D numerically simulated FS for a $3 \mathrm{~mm}$ tubeOJB. Thus we suggest that experimental FSs and/or FS ratios, for various neat and blended HCs with and without additives, offer accurate global tests of chemical kinetic models at the temperatures and pressures of extinction.

Five sets of ASR data representing the hot $(600 \mathrm{~K})$ ternary system of methane + ethylene + $n$-heptane were analyzed comprehensively, using algebraic combinations of least-squares data fits. First, a "best fitting" experimental value of ASR $=1601 / \mathrm{s}$ corresponded to the hot "baseline simulant" (or "reformed fuel") composition (10 mole $\% n$-heptane $+30 \%$ methane $+60 \%$ ethylene) that was originally proposed by Colket and Spadaccini [6] to "mimic" the ignition behavior of an endothermically cracked JP-7 "like" kerosene fuel. Second, it was algebraically determined that a hot binary "FS surrogate" system of $36 \%$ methane $+64 \%$ ethylene has an identical ASR of 160 1/s. A similar determination can be made for a binary ethane + ethylene surrogate that has a nearly constant molecular weight. However, this system has a significantly lower vapor pressure at $300 \mathrm{~K}$ than the methane + ethylene system, and thus, e.g., considerably less gaseous surrogate could be stored in a pressurized bottle of fixed volume.

We continue advocating the Flame Strength approach as a more fundamental and meaningful measurement, for assessing idealized scramjet flameholding potentials, than laminar burning velocity or blowout in a Perfectly Stirred Reactor. This is because the latter characterize premixed combustion in the absence of aerodynamic strain, and FS directly measures a chemical-kinetic-controlled strain-rate-sensitive limit of non-premixed combustion at typical flameholding temperatures. Thus it approximately mimics an idealization of conditions where gaseous fuels are injected into a subsonic flameholding recirculation zone, in which air captured from an upstream inlet system is mixed with the fuel, and the effects of local aerodynamic strain and associated multi-component diffusion on incipient flameholding-combustion are still important.

Based on the above results, we continue advocating that a remotely operated OJB system be developed to achieve real-time (e.g., 1 minute) characterizations of the idealized flameholding potential (FS / ASR) of high-T, high-pressure, multi-component, vaporized-hydrocarbon fuels being used for scramjet testing. This is mainly due to the likelihood of wide variations in fuel composition from test to test. OJB extinction data should also be obtained and compared with other reference sources of vaporized and cracked HCs, e.g., fuels processed by idealized benchtop vaporizer / catalytic cracking systems, or fuels captured by "freezing" the composition of cracked vaporized (superfluid) HCs from other prototype heater / vaporizer / catalytic-cracking systems. Thus we suggest that measurements of FS could be, and should be, a key routine $\mathrm{HC}$ fuel characterization parameter for any scramjet combustor test. Similar logic may be applied to the development of any complex surrogate $\mathrm{HC}$ fuel mixture, such that its measured FS mimics that of a typical uncracked- or cracked fuel, and its FS can, in principal, be numerically simulated using available chemical kinetics and a detailed OJB code. 


\section{References}

1. Spadaccini, L.J., "Autoignition "Characteristics of Hydrocarbon Fuels at Elevated Temperatures and Pressures," ASME Paper No. 76-GT-3, March, 1976, 5 pp.

2. Spadaccini, L.J., and TeVelde, J.A., "Autoignition Characteristics of Aircraft-Type Fuels," Combust. Flame 46, (1982), pp. 283-300.

3. Edwards, T., "USAF Supercritical Hydrocarbon Fuels Interests," AIAA Paper 93-0807, Jan., 1993, 11 pp.

4. Maurice, L.Q., Corporan, E., Minus, D., Mantz, R., Edwards, T., Wohlwend, K. Harrison, W.E., Striebich, R.C., Sidhu, S. Graham, J., Hitch, B., Wickham, D, and Karpuk, M., "Smart Fuels: "Controlled Chemically Reacting Fuels," AIAA Paper AIAA 99-4916, July, 1999, $11 \mathrm{pp}$.

5. Wickham, D.T., Alptekin, G.O., Engel, J.R., and Karpuk, M.E., "Additives to Reduce Coking in Endothermic Heat Exchangers," AIAA Paper AIAA 99-2215, July, 1999, 9 pp.

6. Colket, M.B., III, and Spadaccini, L.J., "Scramjet Fuels Autoignition Study," J.

Propulsion and Power, 17, No. 2, 2001, Mar.-Apr. 2001, pp. 315-323.

7. Gruber, M. Dunbar, J., and Jackson, K., "Newly Developed Direct-Connect HighEnthalpy Supersonic Combustion Research Facility," J. Propulsion and Power, 17, No. 6, Nov.-Dec. 2001, pp. 1296-1304.

8. Mathur, T., Gruber, M., Jackson, K., Donbar, J., Donaldson, W., Jackson, T., and Billig. F., "Supersonic Combustion Experiments with a Cavity-Based Fuel Injector," J. Propulsion and Power, 17, No. 6, Nov.-Dec. 2001, pp. 1305-1312.

9. Quick, A., King, P.I., Gruber, M.R., Carter, C.D., and Hsu, K-Y., "Upstream Mixing Cavity Coupled with a Downstream Flameholding Cavity Behavior in Supersonic Flow," AIAA Paper AIAA-2005-3709, July, 2005, 13 pp.

10. Rasmussen, C.C., Driscoll, J.F., Hsu, Kuang-Yu, Donbar, J.M., Gruber, M.R., and Carer, C.D., "Stability Limits of Cavity-Stabilized flames in Supersonic Flow," Proceedings of the Combustion Institute 30 (2005), 2825-2833.

11. Cooke, J.A., Bellucci, M., Smooke, M.d., Gomez, A., Violi, A., Faravelli, T. and Ranzi, E., "Computational and Experimental Study of JP-8, a Surrogate, and its Components in Counterflow Diffusion Flames," Proceedings of the Combustion Institute 30 (2005), 439-446.

12. Maurice, L.Q, Edwards, T., Cuoco, F. Bruno, C, and Hendrick, P., CHAPTER 2: Fuels, in Technologies for Propelled Hypersonic Flight, RTO-TR-AVT-007, Volume 2 Subgroup 2: Scram Propulsion, ISBNs 978-92-837-0041-4 / 978-92-837-0041-8, Jan. 2006, pp. 2-1 through 2-35.

13. Humer, S., Frassoldati, A., Granata, S., Faravelli, T., Ranzi, E., Seiser, R., Seshadri, K., "Experimental and kinetic modeling study of combustion of JP-8, its surrogates and reference components," Proceedings of the Combustion Institute, 31 (2007), pp. 393-400.

14. Hongzhi, R. Zhang, Eddings, E. G., Sarofim, A.F., "Criteria for selection of components for surrogates of natural gas and transportation fuels," Proceedings of the Combustion Institute, 31 (2007), pp. 401-409. 
15. Valorani, M., Creta, F., Donato, F., Najm, H.N., Goussis, D.A., "Skeletal mechanism generation and analysis for $n$-heptane with CSP," Proceedings of the Combustion Institute, 31 (2007), pp. 483-490.

16. Liu, S., Hewson, J.C., Chen, J.H., "Nonpremixed $n$-heptane autoignition in unsteady counterflow," Combust. Flame 145, (2006), pp. 730-739

17. Holley, A.T., Dong, Y., Andac, M.G., Egolfopoulos, F.N., "Extinction of premixed flames of practical liquid fuels: Experiments and simulations," Combust. Flame 144, (2006), pp. 448-460.

18. Andac, M.G. and Egolfopoulos, F.N., "Diffusion and kinetics effects on the ignition of premixed and non-premixed flames," Proceedings of the Combustion Institute, 31 (2007), pp. $1165-1172$.

19. Pellett, G.L., Isaac, K.M., Humphreys, W.M., Jr., Gartrell, L.R., Roberts, W.L., Dancey, C.L., and Northam, G.B., "Velocity and Thermal Structure, and Strain-Induced Extinction of 14 to $100 \%$ Hydrogen-Air Counterflow Diffusion Flames," Combust. Flame 112, No. 4, 1998, pp. 575-592.

20. Pellett, G.L., Northam, G.B., Guerra, R., and Wilson, L.G., "Opposed Jet Burner Studies of Silane-Methane, Silane-Hydrogen, and Hydrogen Diffusion Flames with Air," CPIA Publication 457, Vol. 1, Oct. 1986, pp. 391-404.

21. Pellett, G.L., Northam, G.B., Wilson, L.G., Jarrett, O., Jr., Antcliff, R.R., Dancey, C.L., and Wang, J.A., "Opposed Jet Diffusion Flames of Nitrogen-Diluted Hydrogen vs. Air:

Axial LDA and CARS Surveys; Fuel/Air Strain Rates at Extinction," AIAA Paper 89-2522, July 1989, $19 \mathrm{pp}$.

22. Guerra, Rosemary, Pellett, G.L., Wilson, L.G., Northam, G.B., "Opposed Jet Burner Studies of Hydrogen Combustion with Pure and $\mathrm{N}_{2}$, NO Contaminated Air," AIAA Paper 87-0090, Jan. 1987, 11 pp.

23. Guerra, Rosemary, Pellett, G.L., Wilson, L.G., Northam, G.B., "Opposed Jet Burner Studies of Effects of $\mathrm{CO}, \mathrm{CO}_{2}$ and $\mathrm{N}_{2}$ Air Contaminants on Hydrogen-Air Diffusion Flames," AIAA Paper 87-1960, July 1987, 14 pp.

24. Pellett, G.L., Jentzen, M.E., Wilson, L.G., and Northam, G.B., "Effects of WaterContaminated Air on Blowoff Limits of Opposed Jet Hydrogen-Air Diffusion Flames," AIAA Paper 88-3295, July 1988, 10 pp.

25. Pellett, G.L., Wilson, L.G., Northam, G.B., Guerra, Rosemary, "Effects of $\mathrm{H}_{2} \mathrm{O}, \mathrm{CO}_{2}$, and $\mathrm{N}_{2}$ Air Contaminants on Critical Airside Strain Rates for Extinction of Hydrogen-Air Counterflow Diffusion Flames," CPIA Publication 529, Vol. II, (Oct., 1989), pp. 23-42. Pasadena, CA, Oct., 1989.

26. Pellett, G.L., Northam, G.B., Wilson, L.G., "Counterflow Diffusion Flames of Hydrogen, and Hydrogen Plus Methane, Ethylene, Propane, and Silane, vs. Air: Strain Rates at Extinction," AIAA Paper 91-0370, Jan., 1991, 17 pp.

27. Pellett, G.L., Northam, G.B., Wilson, L.G., "Strain-Induced Extinction of HydrogenAir Counterflow Diffusion Flames: Effects of Steam, $\mathrm{CO}_{2}, \mathrm{~N}_{2}$, and $\mathrm{O}_{2}$ Additives to Air," AIAA Paper 92-0877, Jan., 1992, 15 pp. (Also a manuscript in preparation on these and recent 2-D numerical results.) 
28. Pellett, G. L., Roberts, W. L., Wilson, L. G., Humphreys, W. M., Jr., Bartram, S. M., Weinstein, L. M., and Isaac, K. M., "Structure of Hydrogen-Air Counterflow Diffusion Flames Obtained by Focusing Schlieren, Shadowgraph, PIV, Thermometry, and Computation," AIAA Paper 94-2300, June 1994, 23 pp.

29. Pellett, G. L., Wilson, L. G., Humphreys, W. M.,Jr., Bartram, S. M., Gartrell, L. R., and Isaac, K. M., Roberts, W. L., IV, and Northam, G. B., "Velocity Fields of Axisymmetric Hydrogen-Air Counterflow Diffusion Flames from LDV, PIV, and Numerical Computation," AIAA paper 95-3112, July 1995, 23 pp.

30. Isaac, K. M., Ho, Y. H., Zhao, J., Pellett, G. L., and Northam, G. B., "Global Characteristics and Structure of Hydrogen-Air Counterflow Diffusion Flames: A One-Dimensional Model," AIAA Paper 94-0680, Jan.,1994. Also, Zhao, J., Isaac, K. M., and Pellett, G. L., J. Propul. Power 12, No. 3: 534-542 (1996).

31. Pellett, G.L., Bruno, C., and Chinitz, W., "Review of Air Vitiation Effects on Scramjet Ignition and Flameholding Combustion Processes," AIAA Paper 2002-3880, July 2002, 37 pp.

32. Pellett, G.L., Bruno, C, and Chinitz, W., CHAPTER 4: Air Vitiation Effects on Scramjet Combustion Tests, in Technologies for Propelled Hypersonic Flight, RTO-TRAVT-007, Volume 2 - Subgroup 4: Scram Propulsion, ISBNs 978-92-837-0041-4 / 97892-837-0041-8, Jan. 2006, pp 4-1 through 4-21.

33. Hwang, Kyu C., "Two Dimensional Numerical Simulation of Highly-Srained Hydrogen-Air Opposed Jet Laminar Diffusion Flames," Ph. D. Dissertation, Old Dominion University, Norfolk, VA, May 2003.

34. Convery, J.L., Pellett, G.L., O' Brien, W.F., and Wilson, L.G., "An Experimental Study of $n$ Heptane and JP-7 Extinction Limits in an Opposed Jet Burner," AIAA Paper 2005-3766, July 2005, 8 pp.

35. Convery, J.L., "An Experimental Investigation of JP-7 and $n$-Heptane Extinction Limits in an Opposed Jet Burner," MS Thesis in Mechanical Engineering, Virginia Polytechnic Institute and State University, Blacksburg, VA, October 27, 2005, 52 pp.

36. Pellett, G.L., Convery, J.L, Wilson, L.G., "Opposed Jet Burner Approach for Characterizing Flameholding Potentials of Hydrocarbon Scramjet Fuels," AIAA Paper 2006-5233, July 2006, 27 pp.

37. Pellett, G.L., Reid, Beth, McNamara, Clare, Johnson, Rachel, Kabaria, Amy, Panigrahi, Babita, and Wilson, L.G., "Acoustic Weakening of Methane-, Ethylene-, and Hydrogen-Air Counterflow Diffusion Flames, and Implications for Scramjet Flameholding." AIAA Paper 20034634, July 2003, 21 pp.

38. Pellett, G., Reid, B., McNamara, C., Johnson, R., Kabaria, A., Panigrahi, B., Sammons, K., and Wilson, L., "Dynamic Weakening of $\mathrm{CH}_{4}-, \mathrm{C}_{2} \mathrm{H}_{6}-$, and $\mathrm{C}_{2} \mathrm{H}_{4} / \mathrm{N}_{2}-$ Air Counterflow Diffusion Flames using Acoustically Perturbed Inflows." Work-in-Progress Poster Paper 4F504, Presented at $30^{\text {th }}$ International Symposium on Combustion, Abstracts of Work-In-Progress Posters, The Combustion Institute, Pittsburgh, PA, July 25-30, 2004.

39. Pellett, G.L., Kabaria, A., Panigrahi, B., Sammons, K., Convery, J., and Wilson, L.G., "Dynamic Weakening (Extinction) of Simple Hydrocarbon-Air Counterflow Diffusion Flames by Oscillatory Inflows." AIAA Paper 2005-4332, July 2005, 22 pp.

40. Pellett, G.L, McNamara, C., Johnson, R., Kabaria, A., Panigrahi, B., Sammons, K., Galgano, J., and Wilson, L.G., "Dynamic Weakening of Gaseous Hydrocarbon (C1-C4)-Air Counterflow 
Diffusion Flames by Oscillatory Inflows," Work-in-Progress Poster Paper 4B01, Presented at $31^{\text {st }}$ International Symposium on Combustion, Abstracts of Work-In-Progress Poster Presentations, The Combustion Institute, Pittsburgh, PA, Aug. 6-11, 2006.

41. Guthhel, E., and Williams, F., $23^{\text {rd }}$ Symposium (International) on Combustion, The Combustion Institute, Pittsburgh, 1990, p. 513.

42. Guthhel, E., Balakrishnan, G., and Williams, F., in Reduced Kinetic Mechanisms for Application in Combustion Systems, Lecture Notes in Physics (N. Peters and B. Rogg, eds.) Springer-Verlag, New York, 1992, p. 177.

43. Pellett, G.L., Isaac, K.M., and Nguyen, G., "Effect of Input Temperature on Strain-Induced Extinction of 50 to $100 \%$ Hydrogen-Air Counterflow Diffusion Flames," Presented at $27^{\text {th }}$ Symposium (International) on Combustion, Abstracts of Work-In-Progress Poster Presentations, The Combustion Institute, Pittsburgh, PA, Poster W2D01, Aug., 1998, p. 192.

44. Rolon, J.C., Veynante, D., Martin, J.P., and Durst, E., "Counter Jet Stagnation Flows," Experiments in Fluids, 11, (1991), pp. 313-324.

45. Spalding, D.B., "Theory of Mixing and Chemical Reaction in the Opposed-Jet Diffusion Flame," J. Amer. Rocket Soc., 3 (1961), pp. 763-771.

46. Williams, F.A., "A Review of Flame Extinction," Fire Safety J., 3 (1981), pp. 163-175.

47. Seiser, R., Truett, L., Trees, D., and Seshadri, K., "Structure and Extinction of Non-premixed $n$-Heptane Flames," $27^{\text {th }}$ Symposium (International) on Combustion, The Combustion Institute (1998), pp. 649-657.

48. Bosschaart, K.J., and de Goey, L.P.H., "The Laminar Burning Velocity of Flames Propagating in Mixtures of Hydrocarbons and Air Measured with the Heat Flux Method," Combustion and Flame, 136 (2004) pp. 261-269.

49. Hassan, M.I., Aung, K.T., Kwon, O.C., and Faeth, G.M., "Properties of Laminar Premixed Hydrocarbon / Air Flames at Various Pressures," J. Propulsion and Power, 14, No. 4 (1998), pp. 479-488.

50. Ciani, Andrea, "Hydrogen and Methane Edge and Diffusion Flames in Opposed Jet Configurations: Structure and Stability." Dissertation, submitted to the Swiss Federal Institute of Technology Zurich, Switzerland, for the degree of Doctor of Technical Sciences, Doctoral Thesis ETH No. 16540, 2006, 108 pp.

51. Zambon, A.C, Chelliah, H.K., "Explicit reduced reaction models for ignition, flame propagation, and extinction of $\mathrm{C}_{2} \mathrm{H}_{4} / \mathrm{CH}_{4} / \mathrm{H}_{2}$ and air systems," Combust. Flame (2007), in press, doi 10 1016/l combustflame 200703003. 


\section{Appendix A - Supporting Strain Rate Characterizations}

\section{Measured and Estimated Strain Rates for Cold Opposed Flows}

Fig. A1 shows our earlier comparisons [36] of Rolon's LDA-measured strain rates (SRs), for varying separations of twin $25 \mathrm{~mm}$ contoured nozzles, and fixed flows of air vs air with balanced axial jet momentum flux [44]. Both the measured radial SR, and $-1 / 2$ the measured axial $S R$ are shown as a function of nozzle separation, $H$. In addition, Spalding's suggested approximation [45] for the radial SR is shown for very large uniform impinging flows, i.e., $U_{\text {air }} / D_{\mathrm{n}}$. Note this approximation has been used by the present authors for some time to represent ASR for convergent nozzles $[19,26,30,36]$, and it is only $\sim 10 \%$ lower than Rolon's measured SRs at $H / D$

$\geq 1$. However, the $2 U_{\text {air }} / H$ approximation developed in [46], which is based on an assumed linear axial velocity gradient, and balanced axial momentum fluxes for cold flows from large matrix type OJBs (typically $22 \mathrm{~mm}$ diameter), produces a SR that is excessively large under typical operating conditions $(H / D \sim 0.45)$. The present authors found the reported SRs from the matrix burner too high by a factor of $\sim 1 / 0.42$, to match (with a short extrapolation) Rolon's measured radial SR (45 $1 / \mathrm{s}$ ) for nozzle-OJB flows. As pointed out by Rolon et. al [44], the $2 U_{\text {air }} / H$ approximation only converges on the measured $-1 / 2$ axial and radial SRs well beyond $H / D>1$, preferably $\geq 1.5$. In our subsequent analyses of tube-OJB data [34-36], and comparison with published $n$ heptane/ $\mathrm{N}_{2}$-air extinction data from a $22 \mathrm{~mm}$ matrix burner [47], we first applied the above correction factor of $1 / 0.42$ to allow for a SR data comparison with nozzle-OJB flows. Then a further factor of 2.5 was applied to tube-OJB results for hydrocarbons, to convert them to equivalent nozzle-OJB results (see Figs. 6 and 5A).

\section{Effect of OJB Tube Diameter in Gaseous Hydrocarbon-Air Systems}

Fig. A2 summarizes the effect of OJB tube diameter on ASR at extinction for five simple gaseous HCs; and Fig. A3 shows the same ASR data plotted versus the product, $U_{\text {air } 300}{ }^{*} D_{\mathrm{t}}$, which is proportional to the Reynolds number for similar gases. Clearly, the use of unnecessarily small tubes produces ASRs that are artificially high, compared to larger tubes, and provided that extinction flows remain laminar. Although a minor crossover of the propane-ethane data occurred near $5 \mathrm{~mm}$ diameter in each figure, relative ASRs among the HC-air systems appear to be maintained with the larger tubes. Tube diameters of $7 \mathrm{~mm}$ and higher resulted in ASRs that effectively attained horizontal asymptotic extinction limits for the five HCs. Basically the same relative effects of OJB size have been found for nozzle-OJBs, as exemplified in Fig. A4 and Fig. 6, and Ref. [19]. Thus idealized Navier Stokes stream function solutions for 1-D centerline-flow boundary conditions appear reasonable for application to "asymptotic" ASR data from the larger tube (and nozzle) sizes and flows [19,36].

Fig. A4 shows $\mathrm{FSs}$ for $\mathrm{N}_{2}$-diluted ethylene-air systems, obtained using a well-characterized $7.2 \mathrm{~mm}$ vertical Pyrex nozzle-OJB with $14 \mathrm{~mm}$ spacing. For this system, an asymptotic FS value for $100 \% \mathrm{C}_{2} \mathrm{H}_{4}$ was estimated, because the $\mathrm{FS}$ of ethylene was so high that the fuel mass flow meter just exceeded its operational limit. Note, the same OJB system has been used extensively to characterize Dynamic Flame Weakening caused by applied sinusoidal velocity inputs of various matched amplitudes, superimposed on steady inflows, with (mostly) in-phase frequencies ranging from 8 to $1600 \mathrm{~Hz}[37-40]$.

\section{Extinction of Pure and $\mathrm{N}_{2}$-diluted Vaporized $n$-Heptane, JP-7 and JP-10 Fuels}

Fig. A5 reproduces the results obtained for vaporized, and also nitrogen-diluted, n-heptane and JP-7 fuels in [34-36]. The apparatus and general procedures used are shown and described in Fig. 1c. The respective ASRs increase substantially with increasing $\mathrm{HC}$ mole fraction, up to 75 mole \%; thereafter, the ASRs attain respective asymptotic values, just like the gaseous HCs and hydrogen fuels do. The asymptotes suggest, as before, that chemical kinetic-limited ASRs 
were attained, because each is unaffected by significant decreases in local nitrogen dilution and diffusion flux. Although these two fuels are of higher molecular weight and lower diffusivity than the gaseous $\mathrm{HCs}$ and $\mathrm{H}_{2}$, and the assumed axial-momentum-balanced flames (w/inputs of $\rho_{\text {air }}$ * $U_{\text {air }}{ }^{2}=\rho_{\text {fuel }}{ }^{*} U_{\text {fuel }}{ }^{2}$ ) should lie closer to the stagnation point, subsequent fuel pyrolysis and combustion-with-diffusion of lower molecular weight fuel species in the airside flame should still be affected by nitrogen dilution and diffusion from the fuel side.

The solid points in Fig. A5, which agree quite closely with the present $n$-heptane data, represent substantial corrections (discussed above) of the experimental extinction strain rate results published by Seiser et. al [47], who used a $22 \mathrm{~mm}$ diameter matrix-OJB with a gap of $H=10 \mathrm{~mm}$. Thus plotted extinction results in [47] were corrected to be comparable with the present ASR scale for a tube-OJB. This correction has two parts, as discussed regarding Fig. A1. First, based on Rolon's measurements of $-1 / 2$ axial and radial SRs as a function of nozzle separation distance [44], a correction factor of $1 / 0.42$ was applied to the Ref. [47] matrix-OJB "global SR" results of $5001 / \mathrm{s}$ for 25 mole $\% n$-heptane/ $\mathrm{N}_{2}$-air, and $4001 / \mathrm{s}$ for 18 mole $\% n$-heptane $/ \mathrm{N}_{2}$-air. The $1 / 0.42$ factor estimates the actual radial (and $-1 / 2$ axial) SRs that existed at $H / D_{\text {burner }}=0.45$, as a correction of the Ref. $[46,47]$ "standard SR expression" for a matrix-type burner, $2 U_{\text {air }} / H$, that assumes a linear SR profile and an axial momentum balance for cold inflows. Next, SRs from the first stage of correction, which allow comparisons with uniform velocity (plug flow) ASRs from a convergent nozzle, were divided by a factor of 2.5. This equals both the experimentally- and numericallyderived factor (discussed above regarding Fig. 6) that converts plug inflow ASRs for hydrocarbonair systems to equivalent parabolic-inflow ASRs with the same radial strain rate in the flame core (see also [33]). As noted earlier, because the equivalent $H / D_{\text {burner }}=0.45$ separation of $11.25 \mathrm{~mm}$ in Fig. A1 is a little smaller than Rolon's smallest separation $(15 \mathrm{~mm})$, and Rolon's flows were cold, the first part of the correction (1/0.42) is a slightly-extrapolated best approximation.

\section{Nitrogen-diluted Hydrogen-Air Systems}

Fig. A6 summarizes all our measured ASRs for extinction of $\mathrm{H}_{2} / \mathrm{N}_{2}$-air CFDFs using tubeOJBs, for a wide range of tube diameters and mostly horizontal orientations. Some upwarddeviations of mid-range results from the two smallest OJBs $(1.8$ and $2.7 \mathrm{~mm}$ ) typify the nonideality (also seen for HCs in Fig. A2) of flames whose thickness is not small compared to tube diameter, especially at reduced Reynolds numbers. Notably these extinction-ASRs for the $\mathrm{H}_{2} / \mathrm{N}_{2}-$ air system using tube-OJBs are substantially lower than ASRs for convergent nozzle-OJBs, as documented earlier $[19,36]$ and illustrated (below) in Fig. A7.

In Fig. A7 the large and slowly changing nozzle-ASR / tube-ASR ratio varies between $\sim 4.2$ and 2.7, as a function of increasing $\mathrm{H}_{2}$ mole fraction for $\mathrm{H}_{2} / \mathrm{N}_{2}$-air systems. This is due to two different effects. First, for identical mass inflows, both axial and radial SRs (and hence respective ASR ratios) were shown in recent 2-D numerical simulations [33] to be 2.5 for parabolic inflow profiles relative to plug flow profiles, regardless of whether the flows were cold and inert, or into a hot $\mathrm{H}_{2}$-air CFDF. Second, the exceptionally high diffusion rate of $\mathrm{H}_{2}$ causes a $\mathrm{H}_{2}$-air flame to locate significantly far on the airside from the stagnation point, compared to a $\mathrm{HC}$-air flame. Thus the maximum radial strain rate achieved in the $\mathrm{H}_{2}$-air flame core is reduced somewhat, relative to what it would be (at the same ASR inflow) if the flame were closer to the stagnation point. And because the rate of diffusion of $\mathrm{HC}$ molecules is generally much lower than for $\mathrm{H}_{2}$, airside $\mathrm{HC}$ flames locate significantly closer to the stagnation point, where radial SRs happen to be closer to being ideal for 1-D models [19]. Thus the ASR extinction ratios for all six of the present HCs are clustered near (just below) 2.5, which is in agreement with Hwang's [33] numerically simulated values of 2.5 for both cold and hot parabolic / plug inflows. 


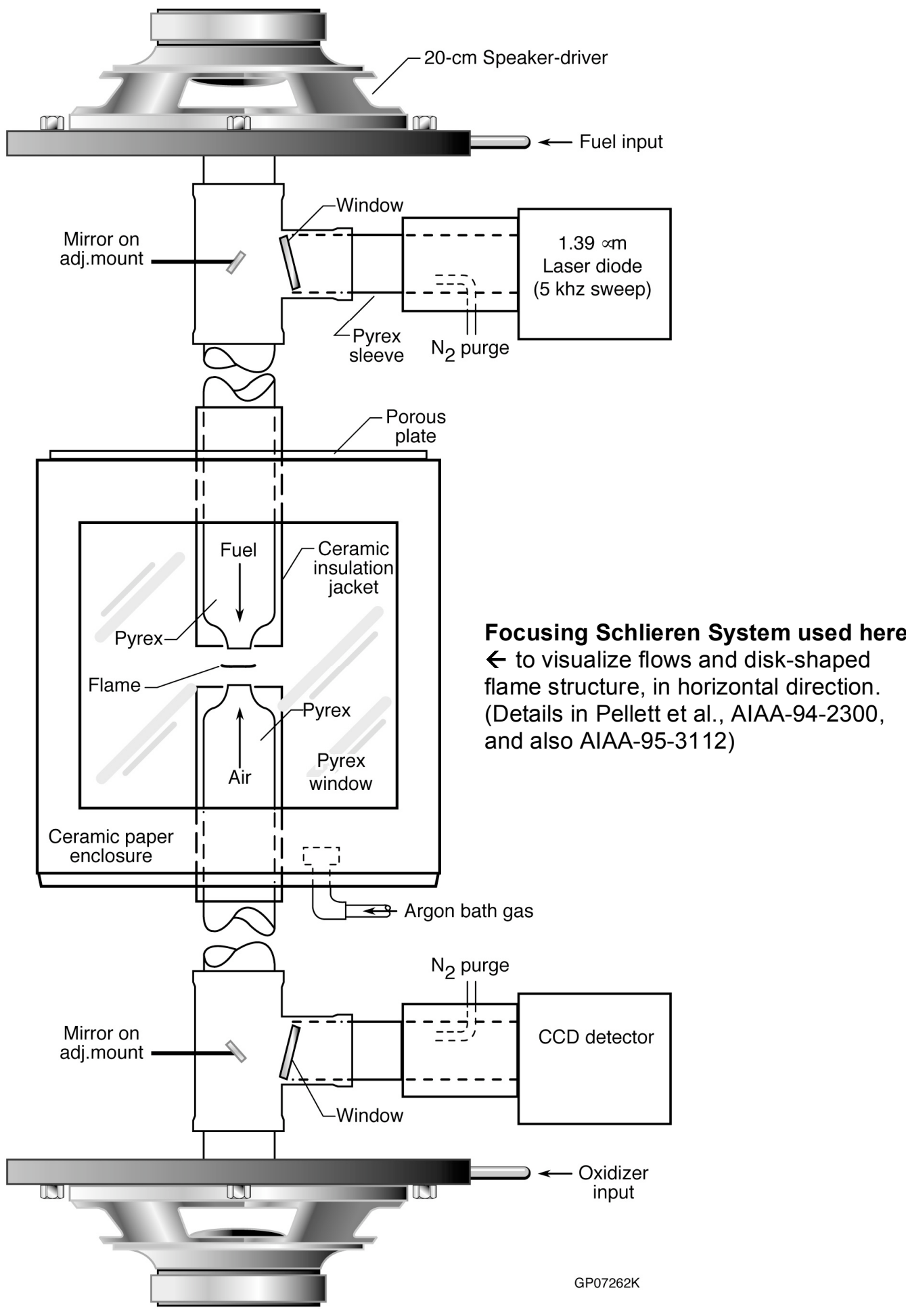

Fig. 1a. Schematic of Oscillatory Opposed Jet Burner (OOJB) system with twin $20-\mathrm{cm}$ speaker-drivers. Diode laser system is passive in this study. 


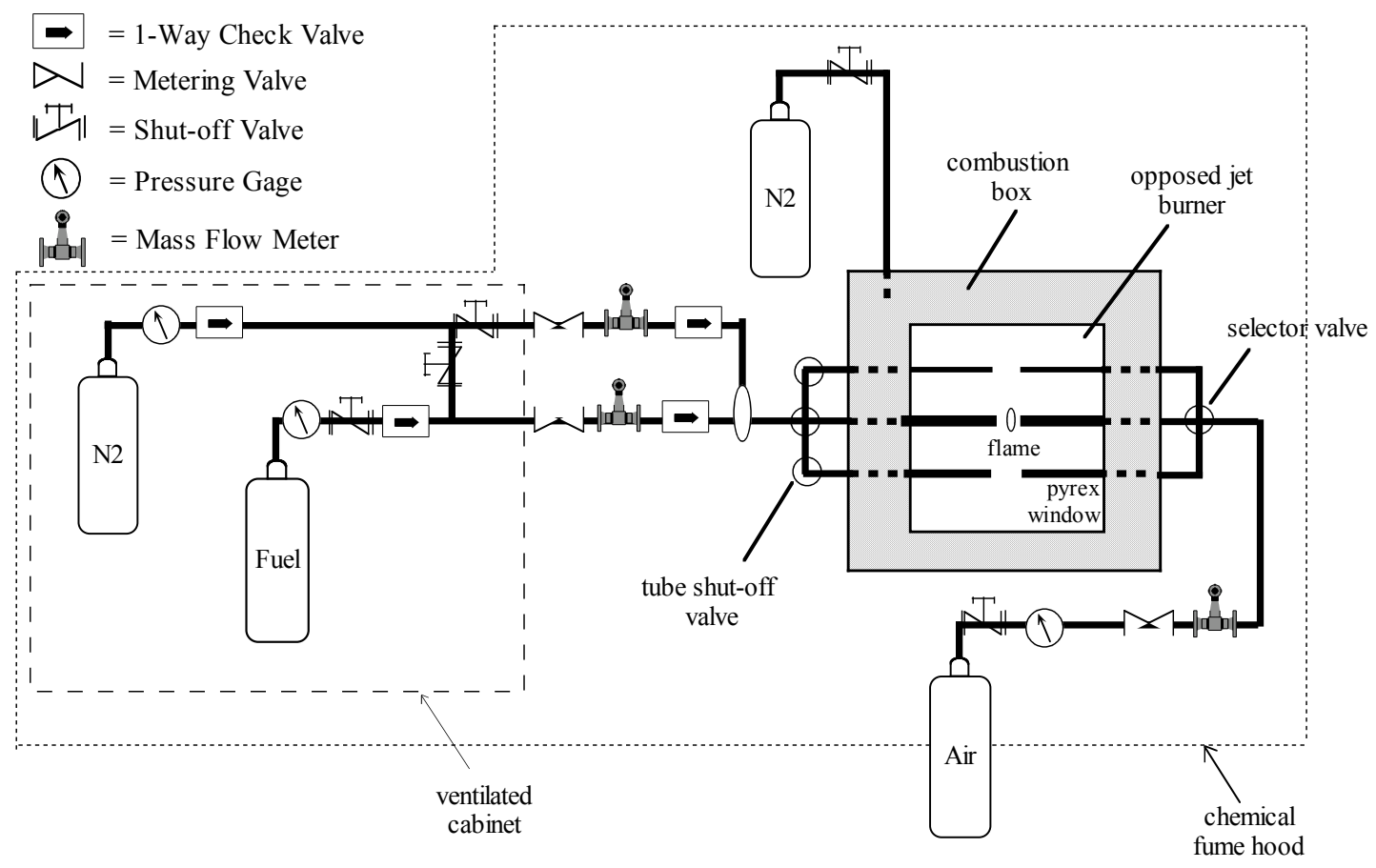

Fig. 1b. Gaseous-fuel horizontal-tube OJB test schematic (not to scale). Combustion box, constructed of 0.5 in thick compacted silica fiber-board panels, has a porous metal plate on top -- typically $4 \times 6$ in -- is exposed and "active". Thus combustion products are actively purged by controlled nitrogen flows from two porous plug outlets at opposite corners of the box floor. The three matching sets of tube-OJBs are actually arrayed in a horizontal plane, not vertically as shown. Mass flows of fuel, fuel-diluent, and air are monitored as flame extinction and restoration limits are approached and achieved.

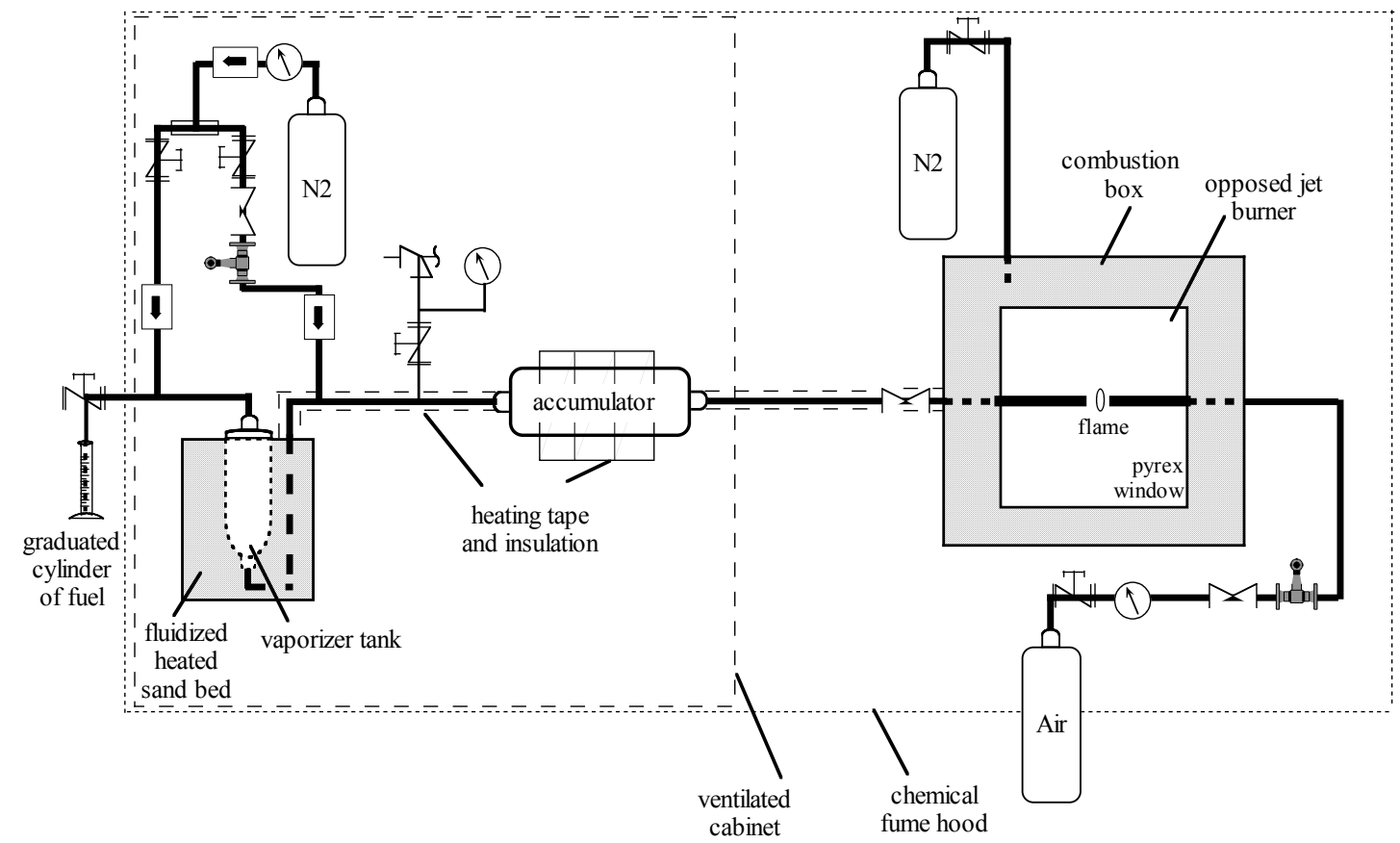

Fig. 1c. Liquid-fueled OJB test schematic (not to scale). Silica fiber combustion box, with porous plate on top, is identical to that in Fig. 1b. Vaporizer tank is $\sim 0.5 \mathrm{~L}$ and accumulator tank is $\sim 10.1 \mathrm{~L}$. For each batch test (set), a known volume of liquid $\mathrm{HC}$ is injected into the cold, evacuated system. Then mass-flow-metered fuel diluent (either $\mathrm{N}_{2}$ or gaseous $\mathrm{HC}$ ) is admitted, up to a specific pressure. Finally, the system is sealed and heated to a measured (multipoint) temperature and pressure, and held there to assure mixing before it is operated in a "blow down mode," to supply the $7.5 \mathrm{~mm}$ tube-OJB system. For the hot vaporized-fuel experiments, air mass flows are monitored, but mass flows of fuel mixture are not monitored due to temperature limitations. 


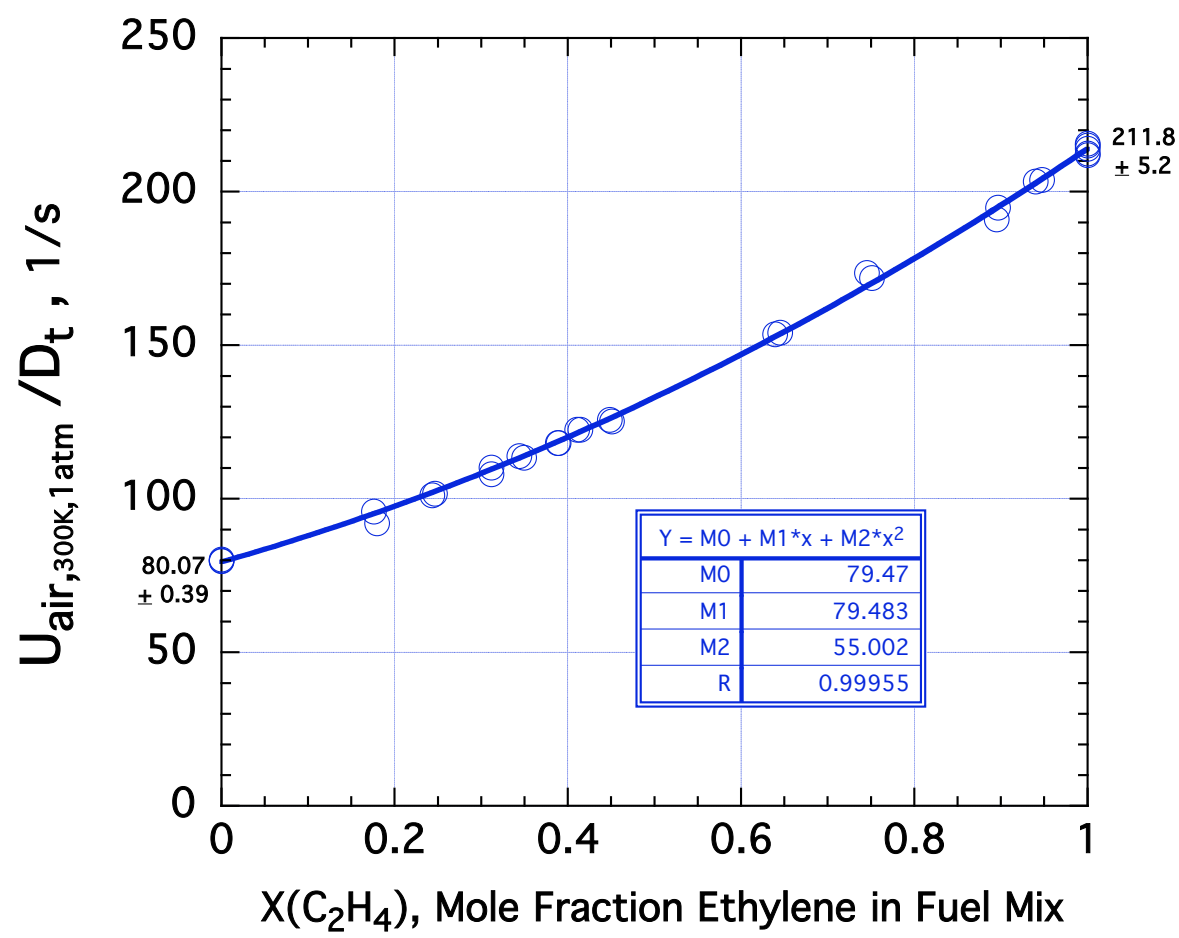

Fig. 2. Applied Stress Rate (ASR) at extinction for Methane + Ethylene fuel mix vs Air CFDFs; $7.56 \mathrm{~mm}$ tube-OJB with $1 \mathrm{~atm}, 300 \mathrm{~K}$ inputs.

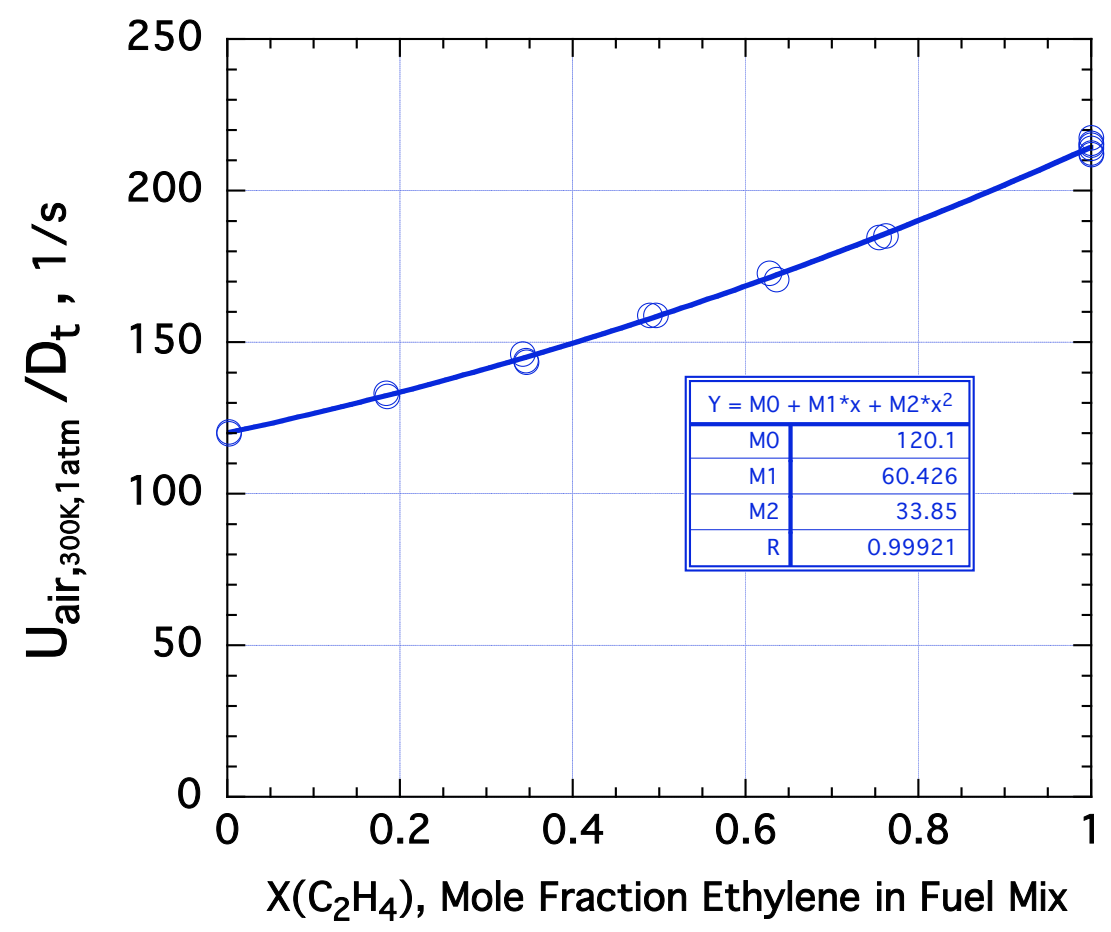

Fig. 3. ASR at extinction for Ethane + Ethylene fuel mix vs Air CFDFs; $7.56 \mathrm{~mm}$ tube-OJB with $1 \mathrm{~atm}, 300 \mathrm{~K}$ inputs. 


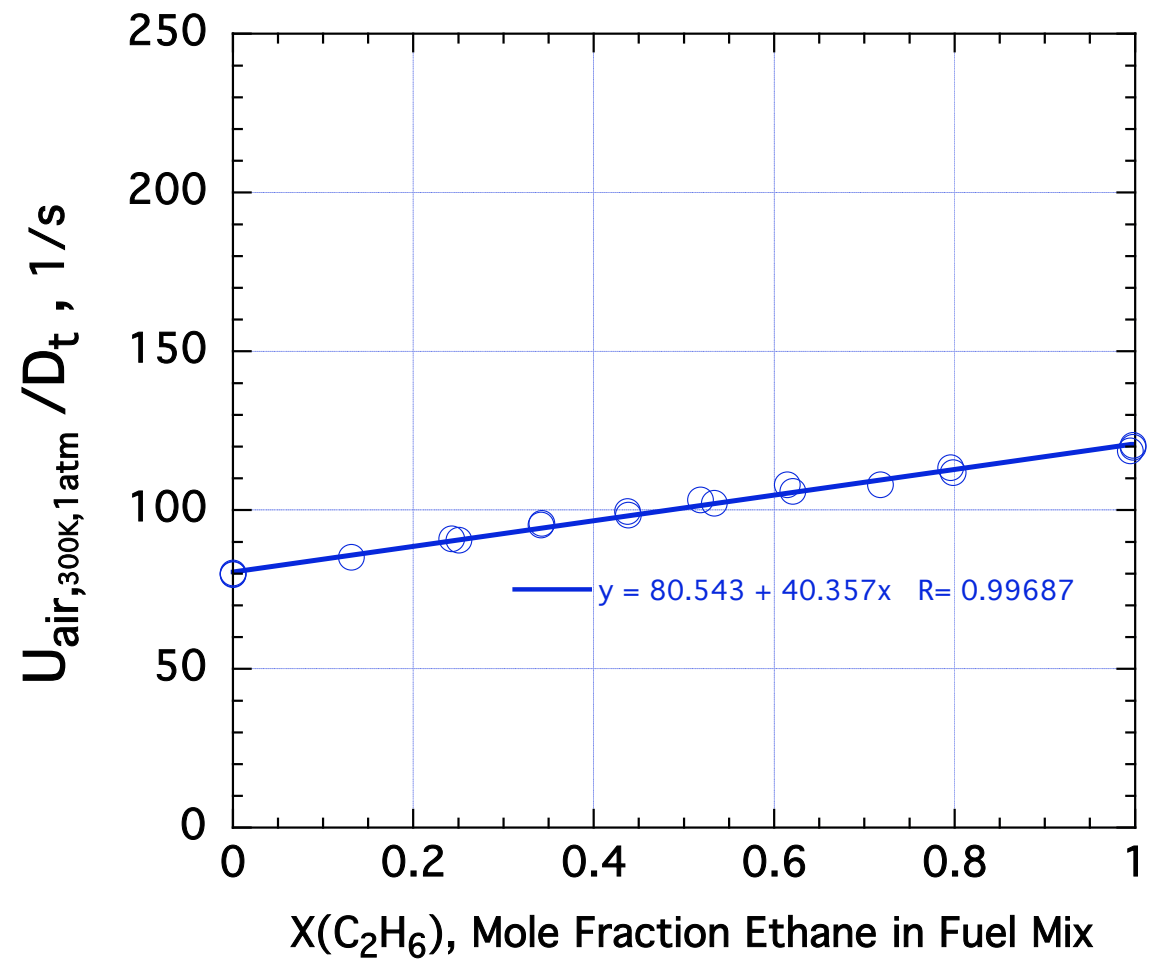

Fig. 4. ASR at extinction for Methane + Ethane fuel mix vs Air CFDFs; $7.56 \mathrm{~mm}$ tube-OJB with $1 \mathrm{~atm}, 300 \mathrm{~K}$ inputs.

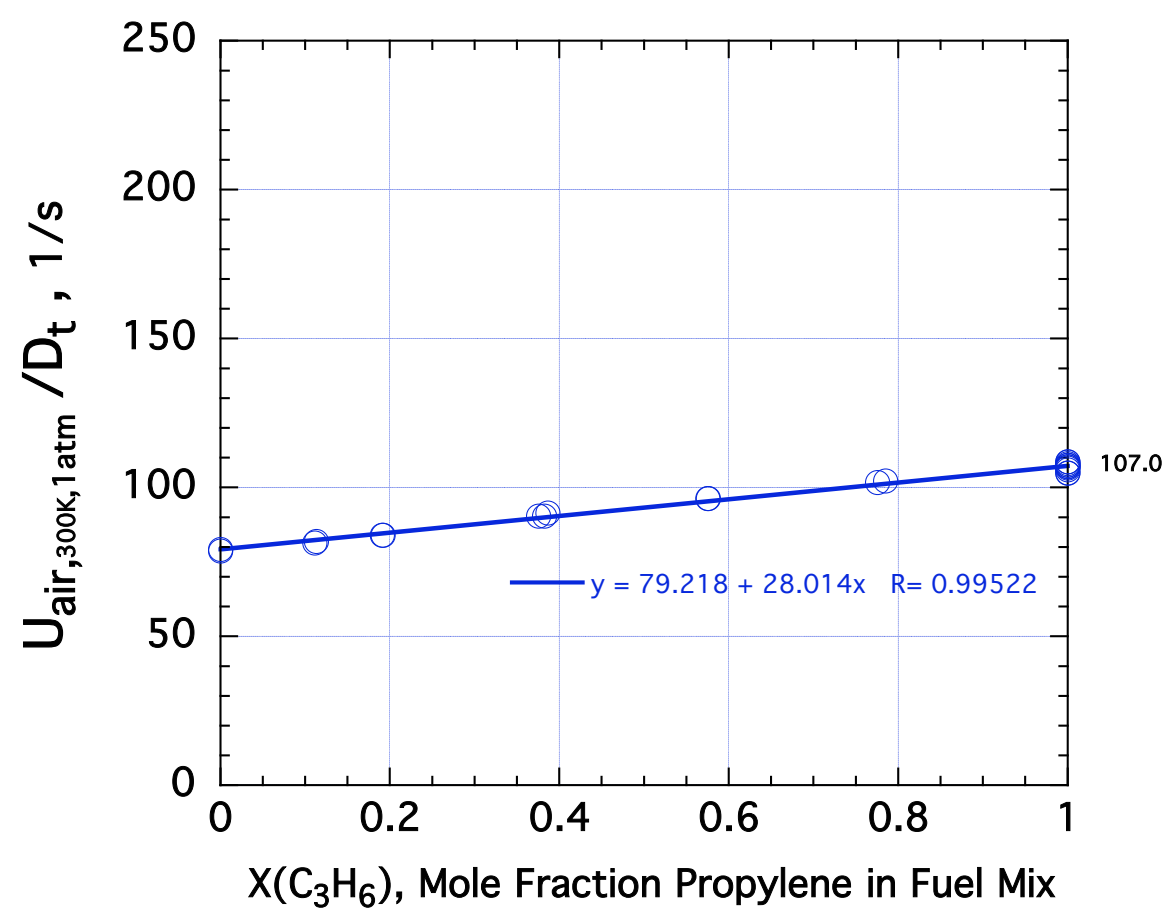

Fig. 5. ASR at extinction for Methane + Propylene fuel mix vs Air CFDFs; $7.56 \mathrm{~mm}$ tube-OJB with $1 \mathrm{~atm}, 300 \mathrm{~K}$ inputs. 


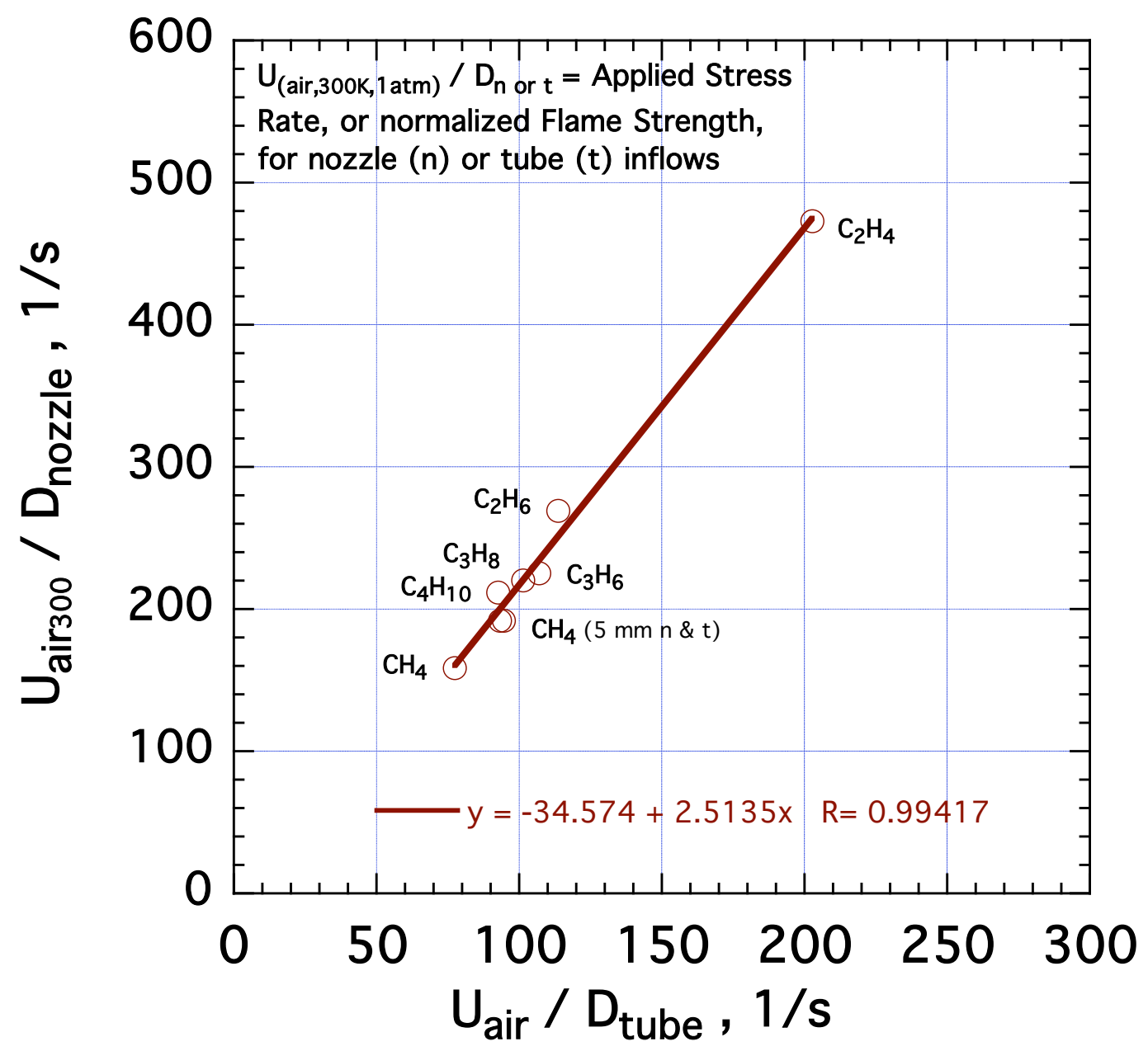

Fig. 6. OJB-extinction-limit "Idealized Flameholding Scale," from $7.2 \mathrm{~mm}$ convergent nozzle- and 7.5 $\mathrm{mm}$ straight-tube-OJBs, for Methane, Butane, Propane, Propylene, Ethane, and Ethylene-Air CFDFs, with $1 \mathrm{~atm}, 300 \mathrm{~K}$ Air inputs. Note the 2.51 linear slope is consistent with parabolic-inflow / plug-inflow SR measurements (2.5) for equivalent $\mathrm{H}_{2} / \mathrm{N}_{2}$-Air CFDFs [29,19,36], and with numerical 2-D simulations (2.5) for both identical average cold inflows [33], and for LDV and PIV measurements of axial SRs of equivalent CFDFs. 


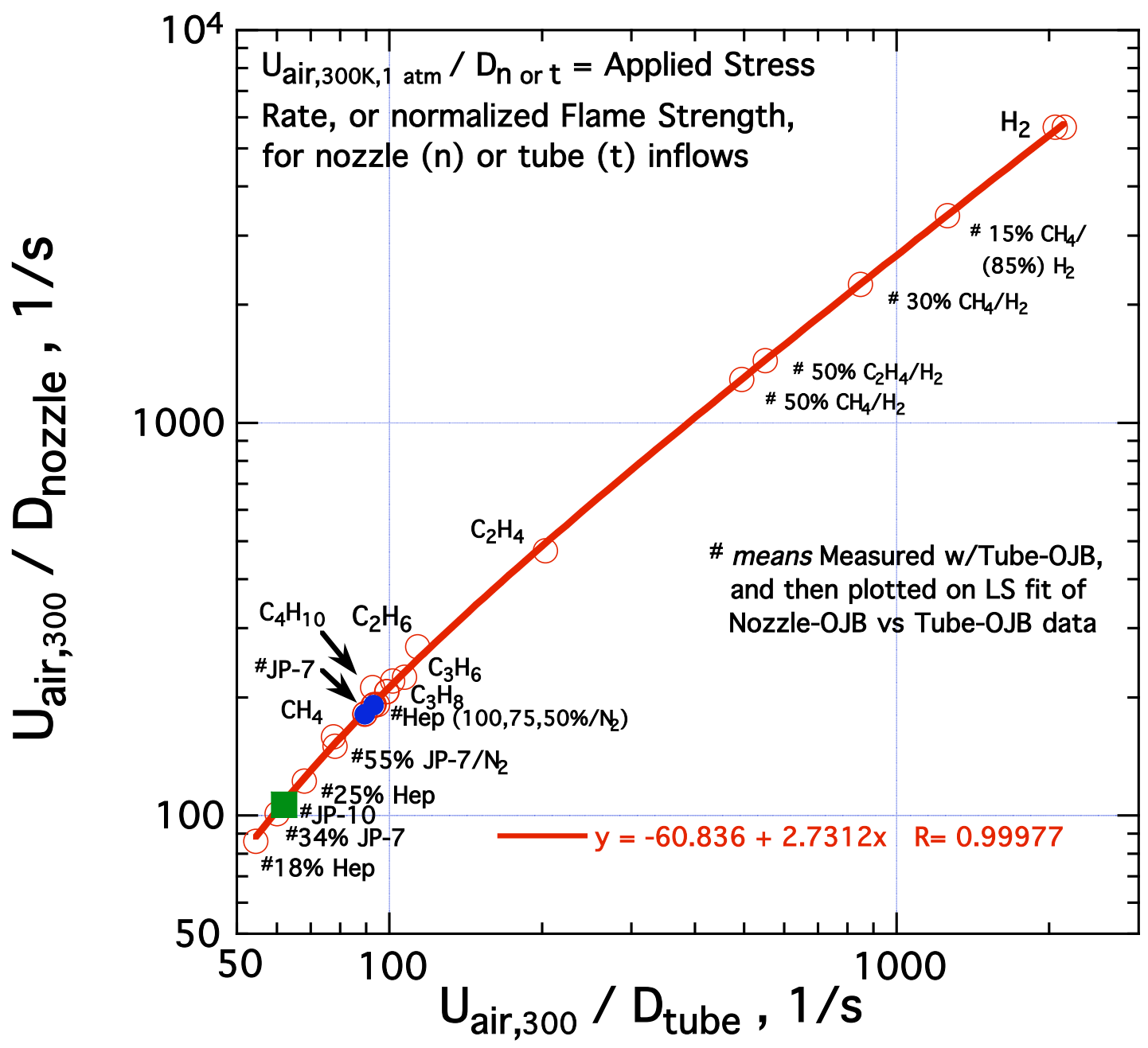

Fig. 7. OJB-extinction-limit "Idealized Flameholding Scale" from convergent-nozzleand straight-tube-OJBs, for JP-7, JP-10 and $n$-Heptane / $\mathrm{N}_{2}$; and Methane, Butane, Propane, Propylene, Ethane, Ethylene, and Hydrogen-Air CFDFs, with $1 \mathrm{~atm}, 300$ $\mathrm{K}$ inputs. 


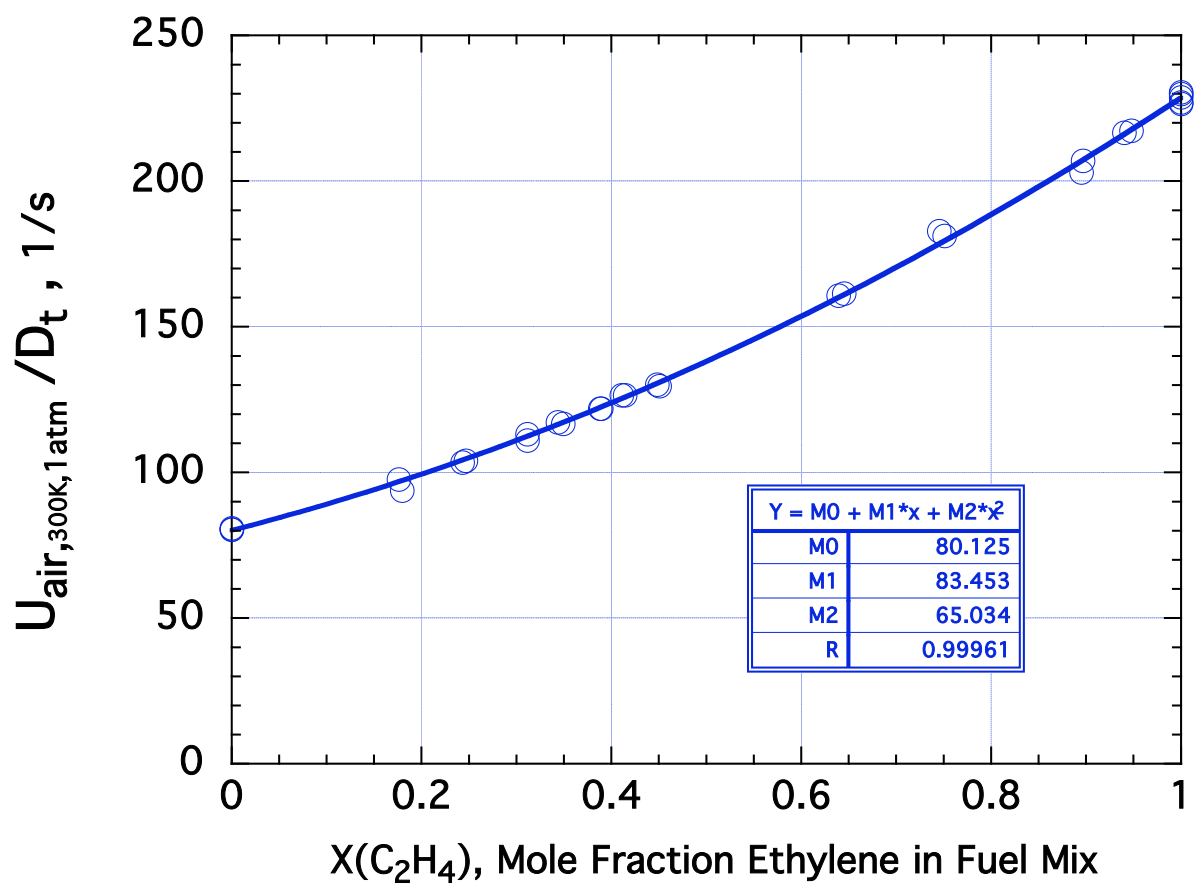

Fig. 8. ASR at extinction for $600 \mathrm{~K}$ Methane + Ethylene fuel mix vs Air CFDFs; $7.56 \mathrm{~mm}$ tube-OJB with $1 \mathrm{~atm}, 300 \mathrm{~K}$ air inputs.

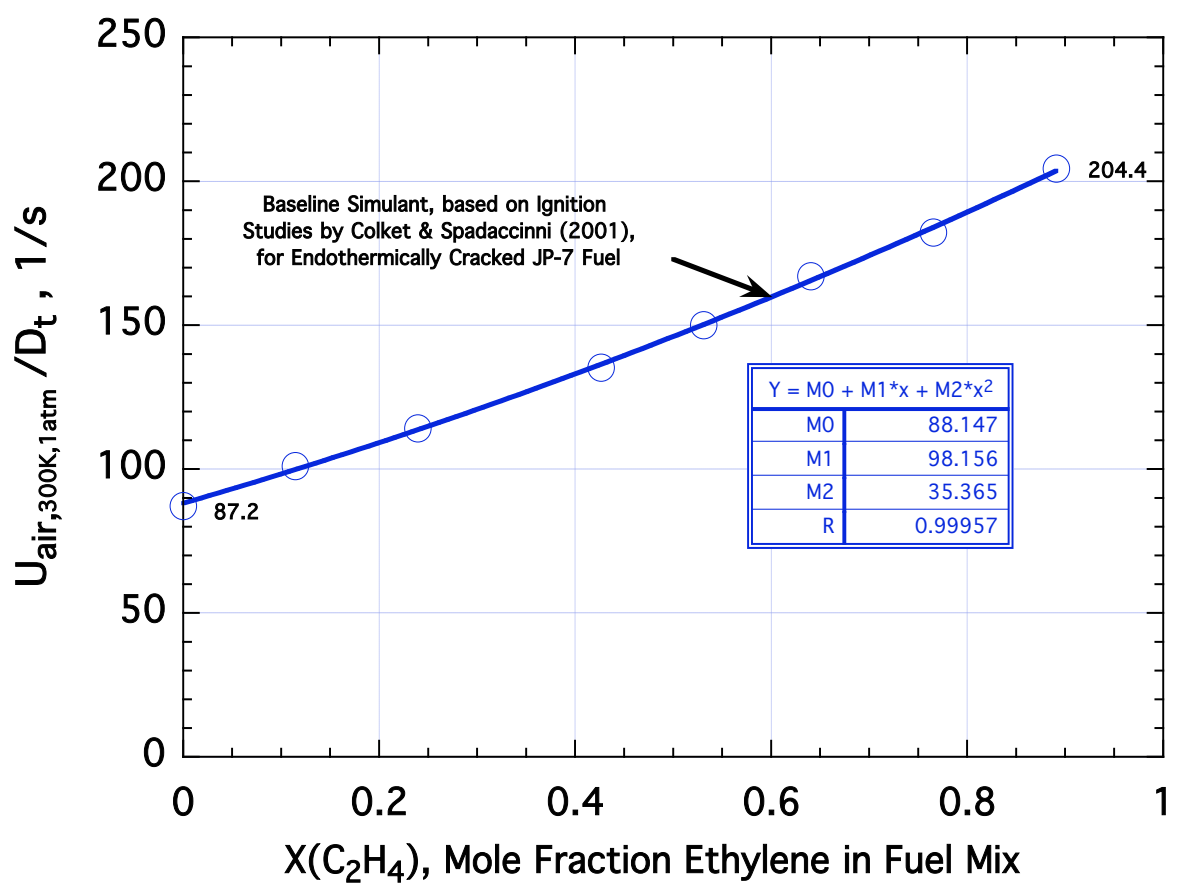

Fig. 9. ASR at extinction for $600 \mathrm{~K}$ Methane + Ethylene $+\mathbf{1 0 . 8}$ mole $\% n$-Heptane gaseous fuel mix vs Air CFDFs; $7.56 \mathrm{~mm}$ tube-OJB with $1 \mathrm{~atm}, 300 \mathrm{~K}$ air inputs. 


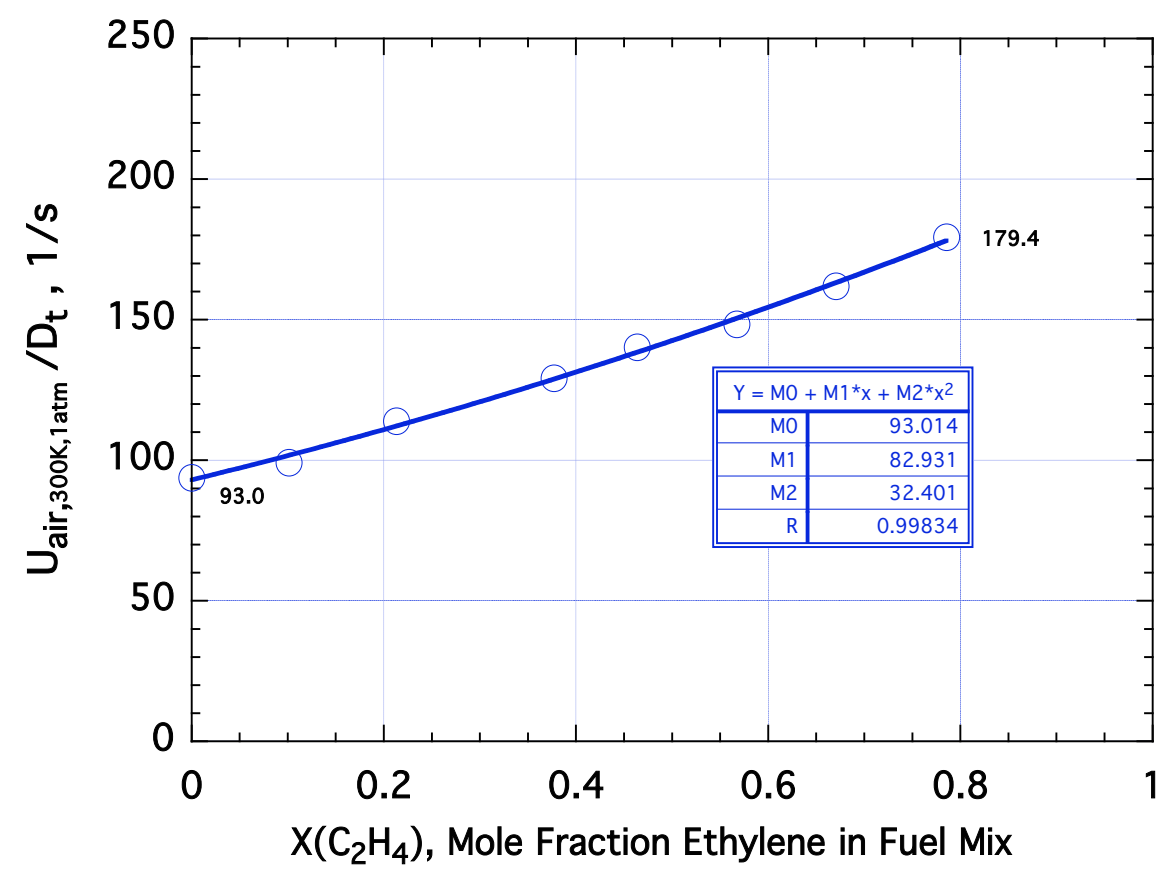

Fig. 10. ASR at extinction for $600 \mathrm{~K}$ Methane + Ethylene $+\mathbf{2 1 . 3}$ mole $\% \boldsymbol{n}$-Heptane gaseous fuel mix vs Air CFDFs; $7.56 \mathrm{~mm}$ Tube-OJB with $1 \mathrm{~atm}, 300 \mathrm{~K}$ air inputs.

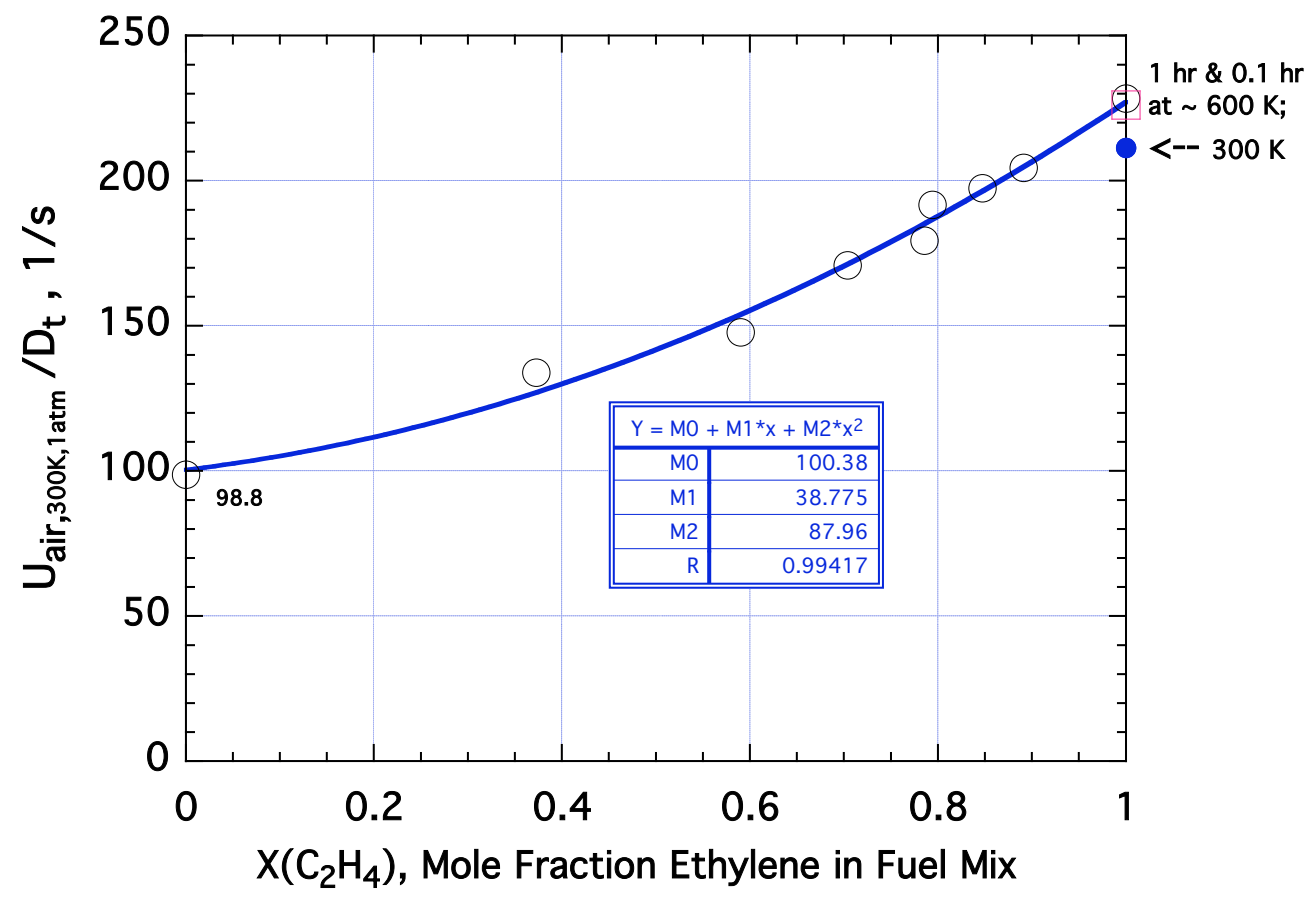

Fig. 11. ASR at extinction for $600 \mathrm{~K} \boldsymbol{n}$-Heptane + Ethylene gaseous fuel mix vs Air CFDFs; $7.56 \mathrm{~mm}$ tube-OJB with $1 \mathrm{~atm}, 300 \mathrm{~K}$ air inputs. 


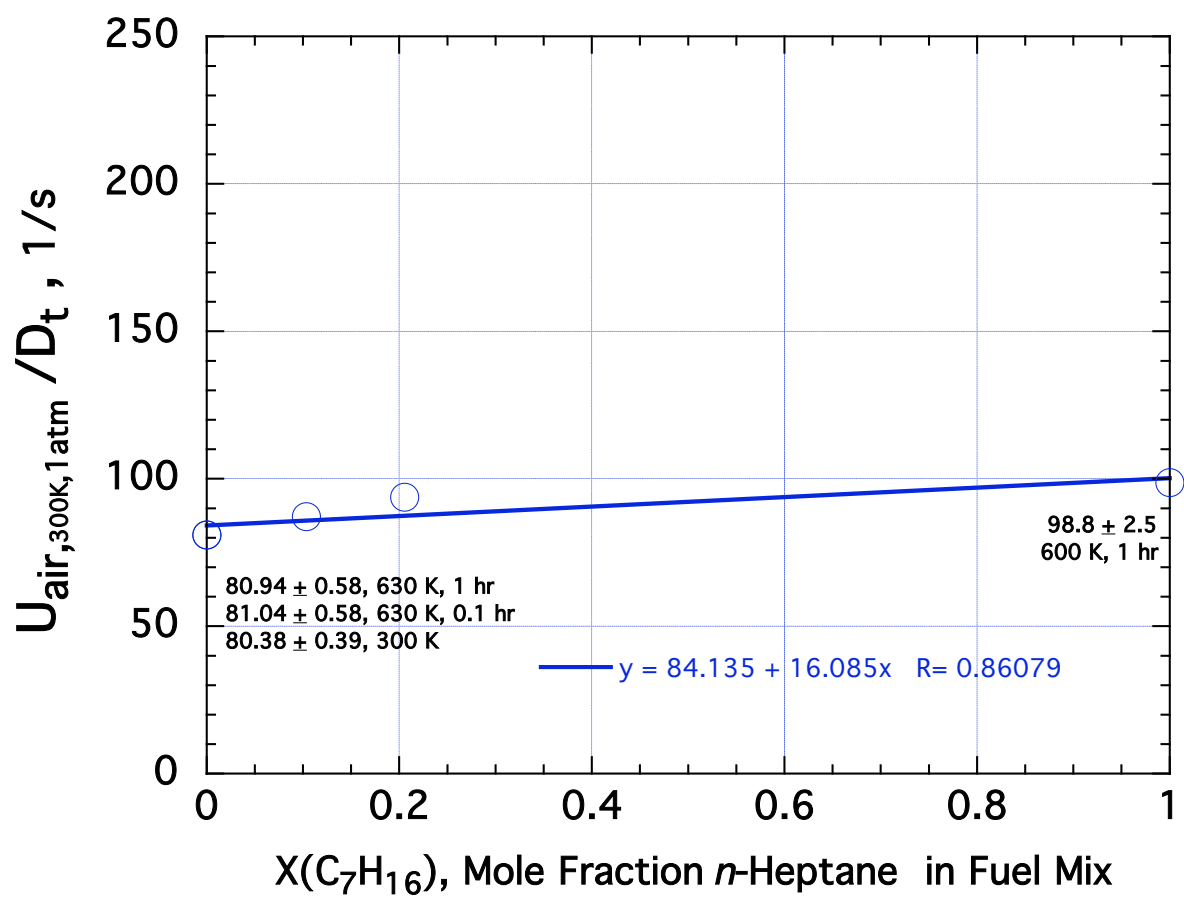

Fig. 12. ASR at extinction for $600 \mathrm{~K} n$-Heptane + Methane fuel mix vs Air CFDFs; $7.56 \mathrm{~mm}$ tube-OJB with $1 \mathrm{~atm}, 300 \mathrm{~K}$ Air Inputs. Note the very small effect of heating methane for $0.1 \mathrm{hr}$ or $1 \mathrm{hr}$ times. 


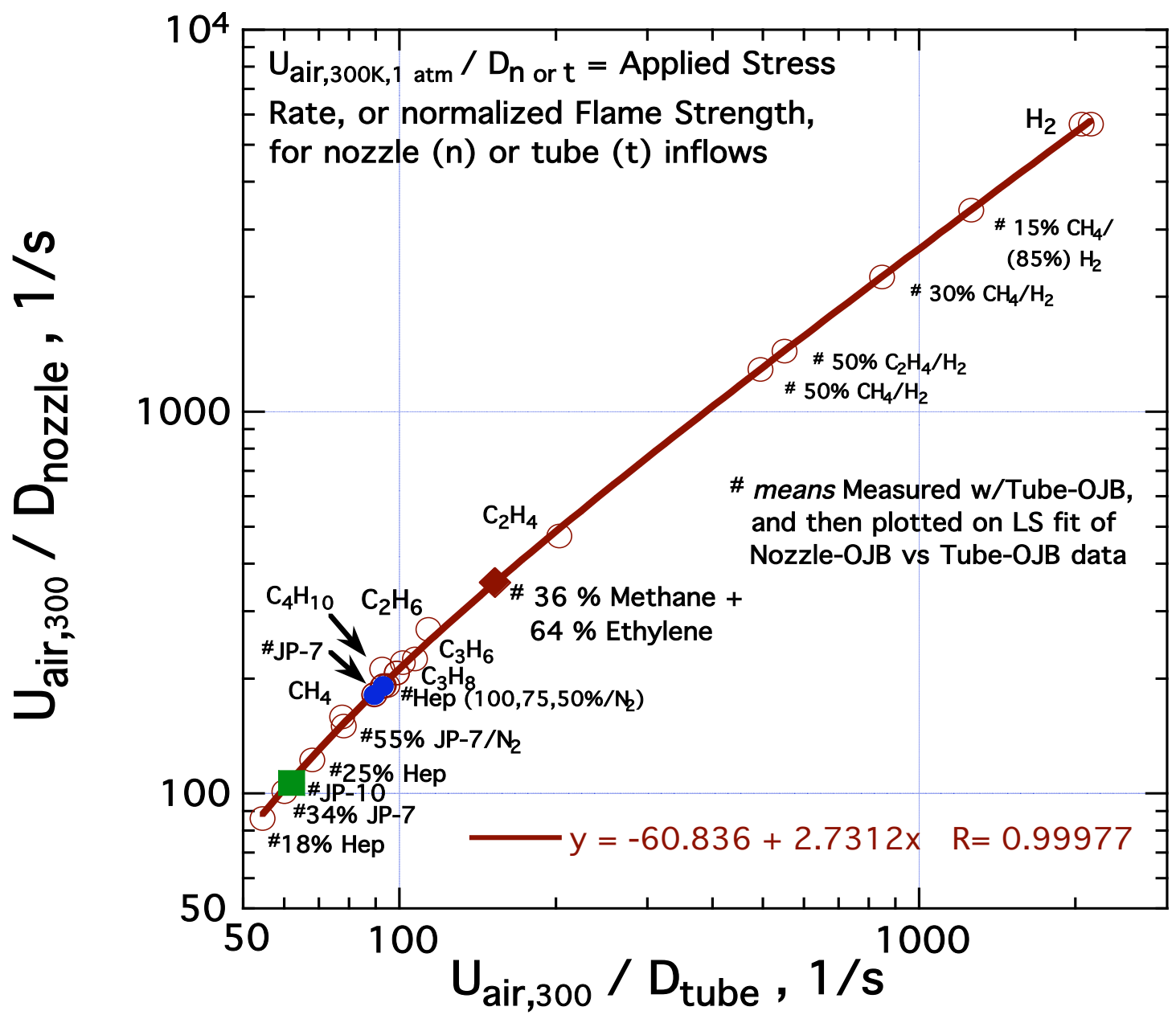

Fig. 13. Updated OJB-Extinction-Limit "Idealized Flameholding Scale" from convergentnozzle- and straight-tube-OJBs, for JP-7, JP-10 and $n$-Heptane / Nitrogen; and Methane, Butane, Propane, Propylene, Ethane, Ethylene, Hydrogen-Air, and mixed HC-Air CFDFs. Note the presently defined binary surrogate fuel mixture located at $A S R_{t}=1601 / \mathrm{s}$. 


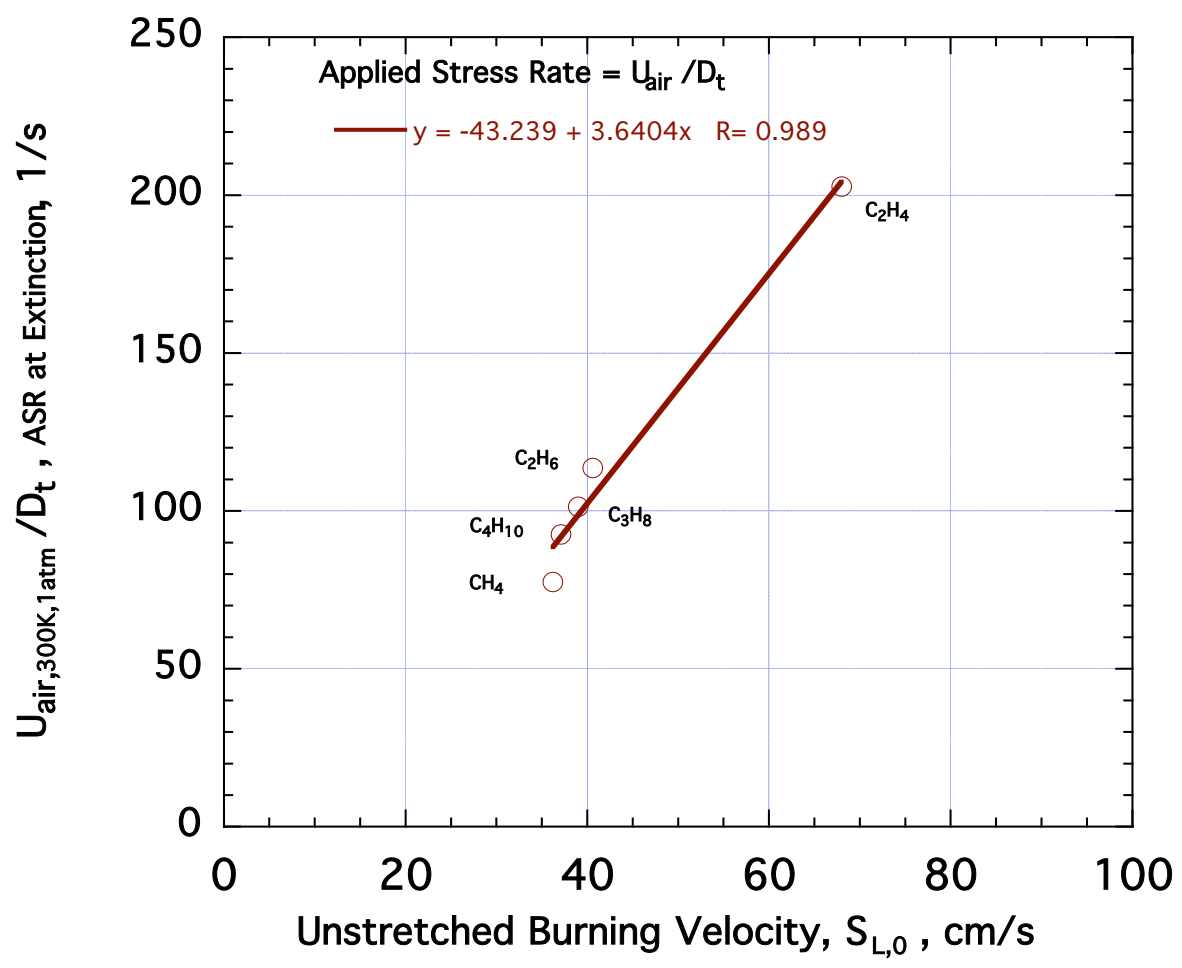

Fig. 14. Comparison of extinction limits, from $7.5 \mathrm{~mm}$ tube-OJB, with unstretched Laminar Burning Velocity at phi $=1$, for Methane, Ethane, Propane, Butane and Ethylene-Air flames.

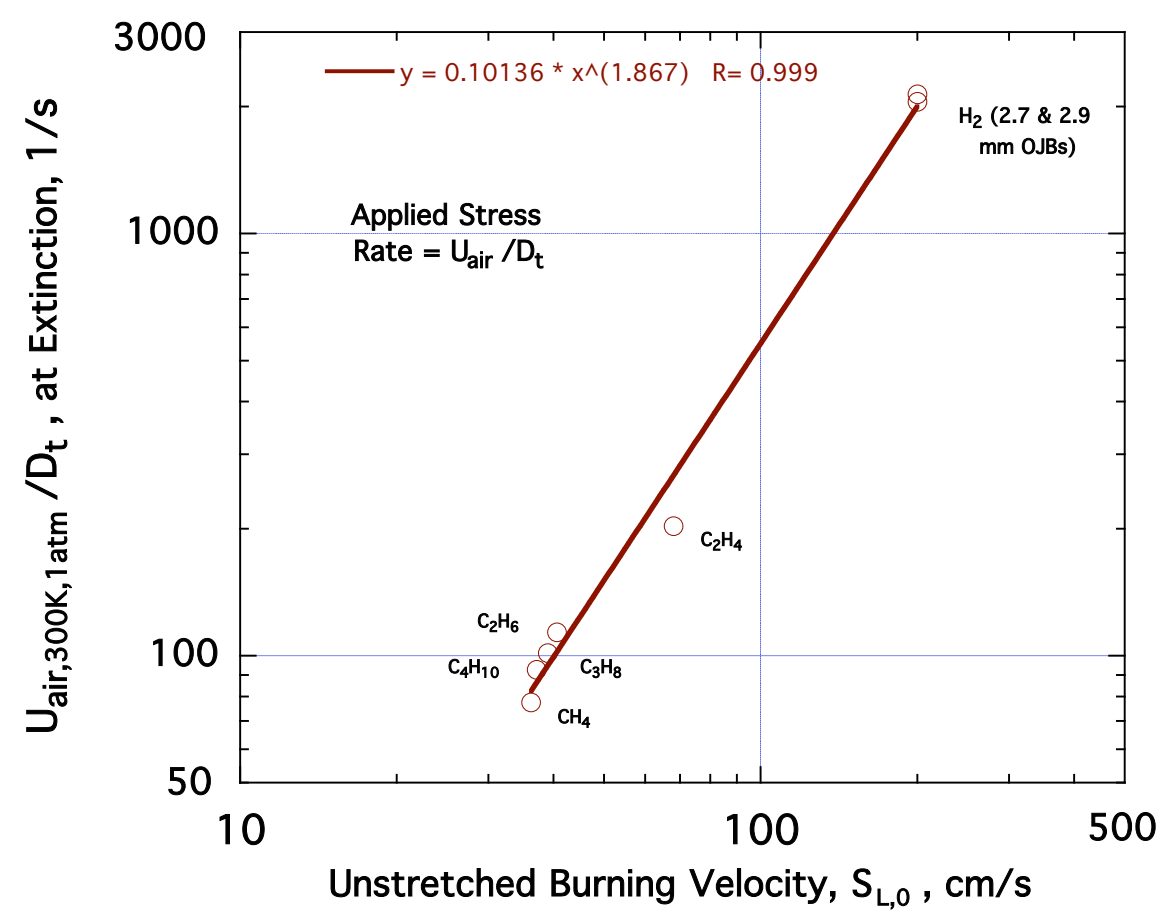

Fig. 15. Comparison of extinction Limits, from $7.5 \mathrm{~mm}$ tube-OJB, with Un-Stretched Laminar Burning Velocity at phi $=1$, for Methane, Ethane, Propane, Butane, Ethylene and $\mathrm{H}_{2}$-Air flames. 


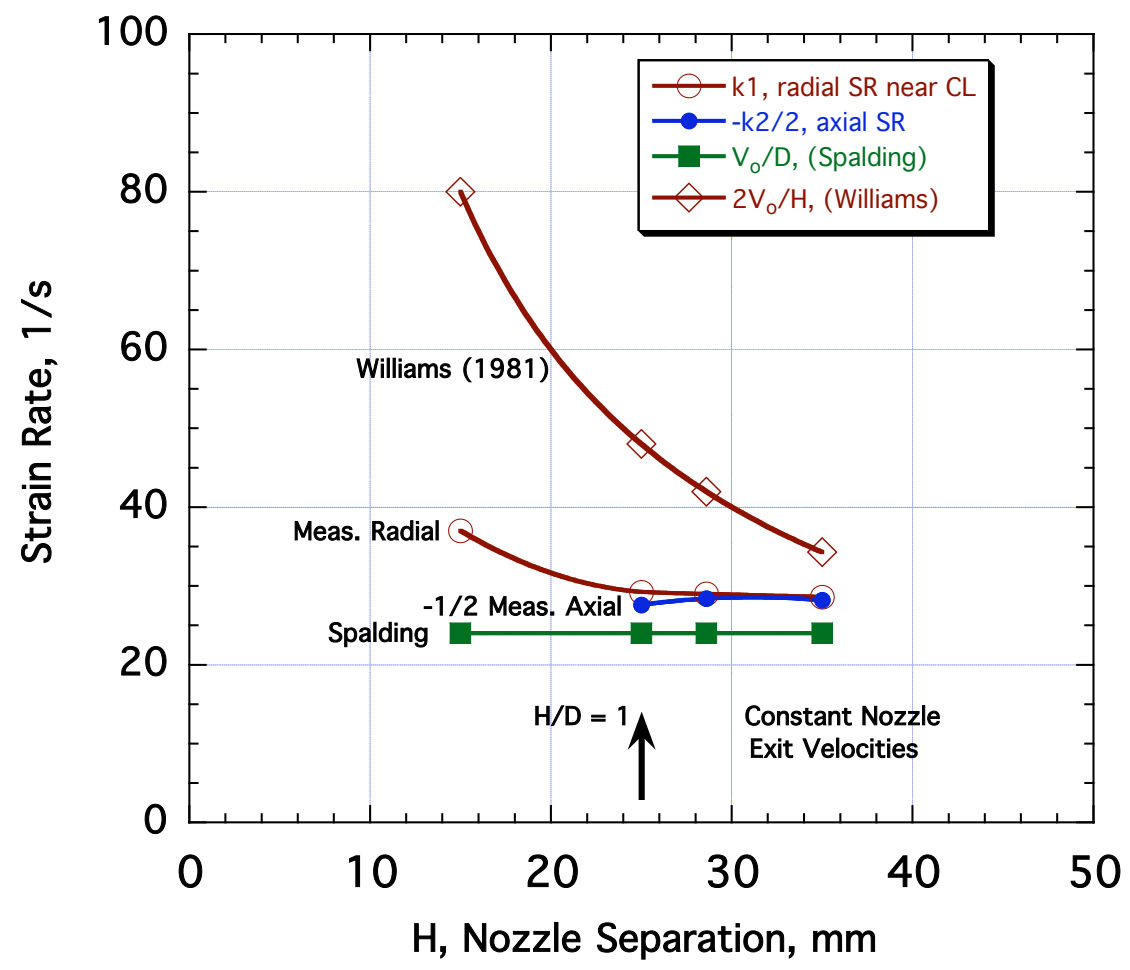

Fig. A1. Comparison of Rolon's LDA-measured Strain Rates for variable separation of $25 \mathrm{~mm}$ contoured nozzles, Air vs Air [44]. For $H / D \geq 1$, the radial and $-1 / 2$ axial strain rates approximately equal $1.1 V_{\mathrm{o}} / D\left(=1.1 U_{\text {air }} / D_{\mathrm{n}}\right)$, which agrees with recent numerical simulations [33].

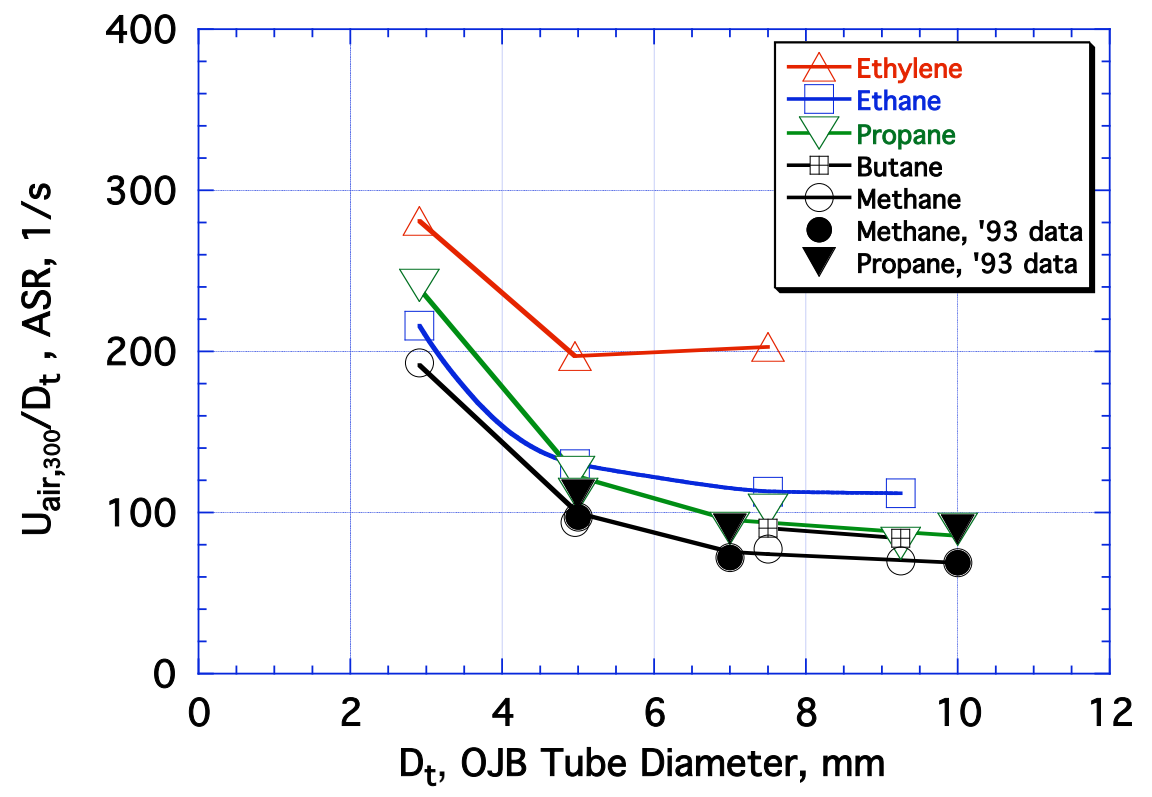

Fig. A2. Asymptotic approach of Applied Stress Rates (ASRs) at extinction vs OJB tube diameter, for various gaseous HC vs Air CFDFs with $1 \mathrm{~atm}, 300 \mathrm{~K}$ inputs. 


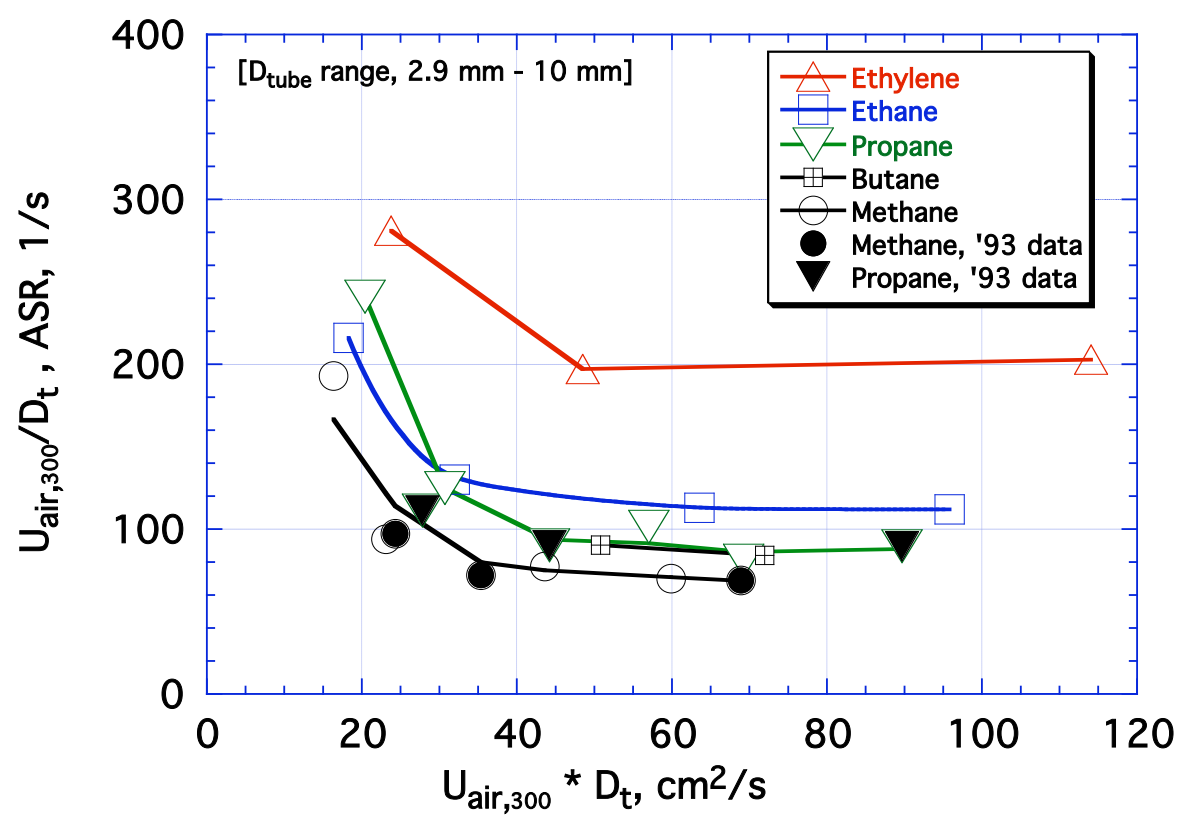

Fig. A3. Asymptotic approach of ASRs at extinction vs exit-velocity * tube-diameter product $(\sim R e)$, for various gaseous $\mathrm{HC}$ vs Air CFDFs with $1 \mathrm{~atm}, 300 \mathrm{~K}$ inputs.

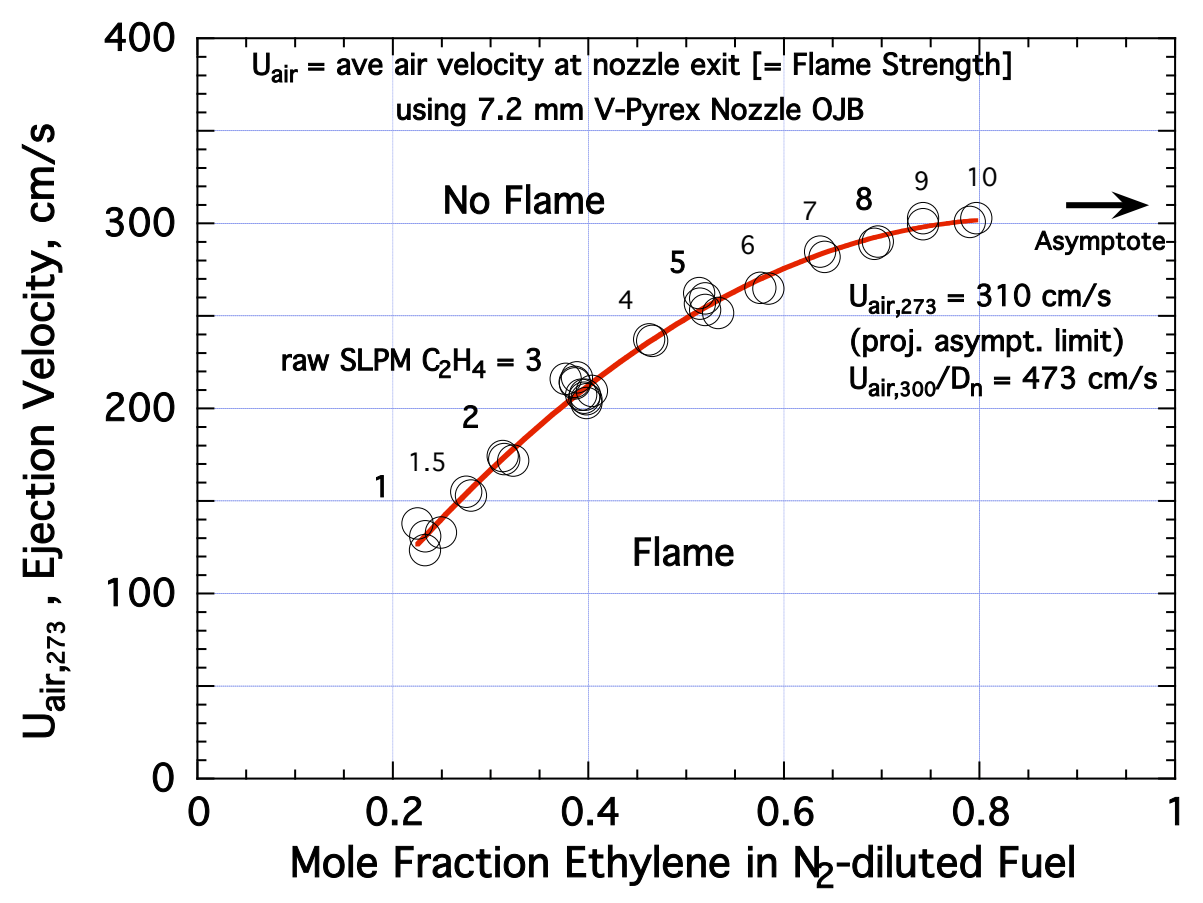

Fig. A4. Steady-state extinction of $\mathrm{C}_{2} \mathrm{H}_{4} / \mathrm{N}_{2}$-Air CFDFs, using 7.2 $\mathrm{mm}$ vertical-Pyrex nozzle Oscillatory-OJB system. 


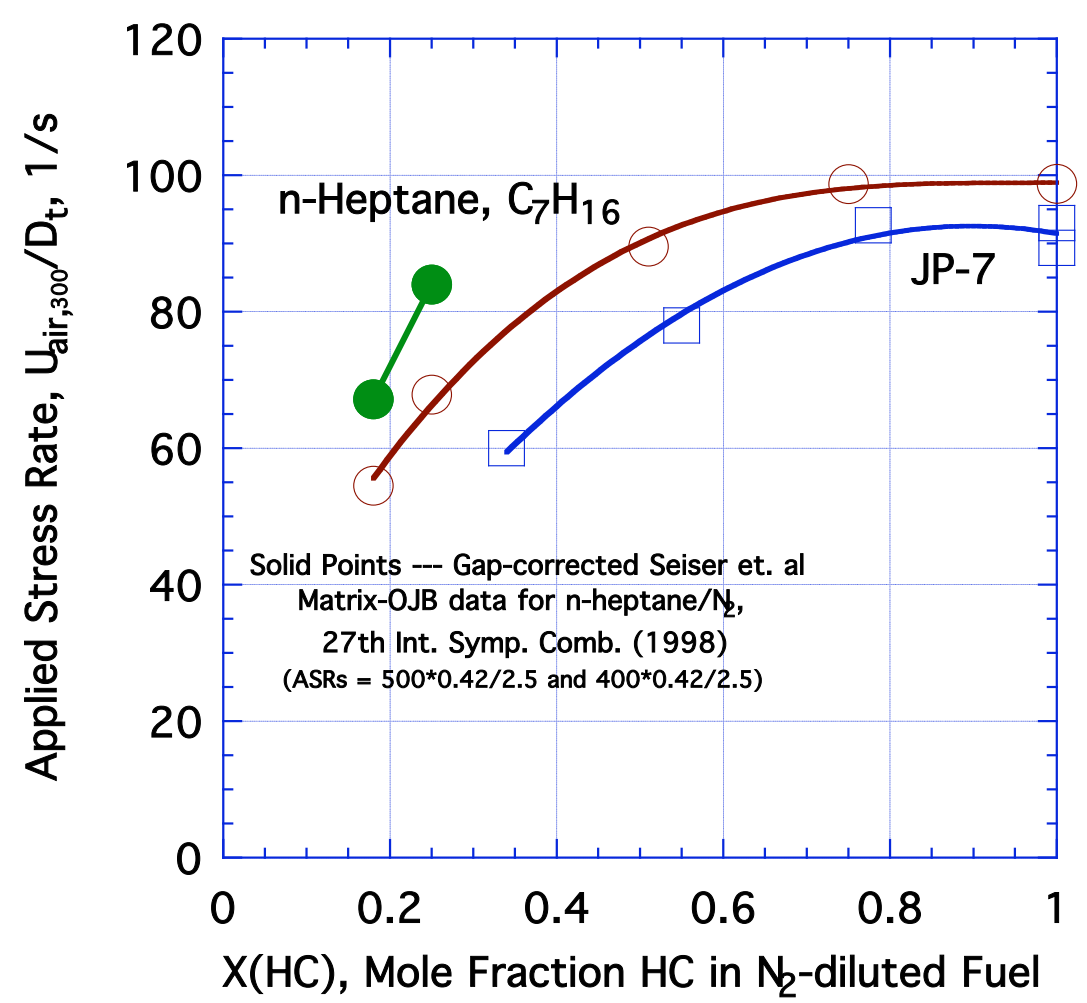

Fig. A5. Extinction of $n$-Heptane/ $\mathrm{N}_{2}-$ Air and JP-7/ $\mathrm{N}_{2}-$ Air CFDF's, using $7.50 \mathrm{~mm}$ tube-OJB with "batch" vaporizer system; and comparison with gap-corrected $n$-heptane data from Seiser et. al [47].

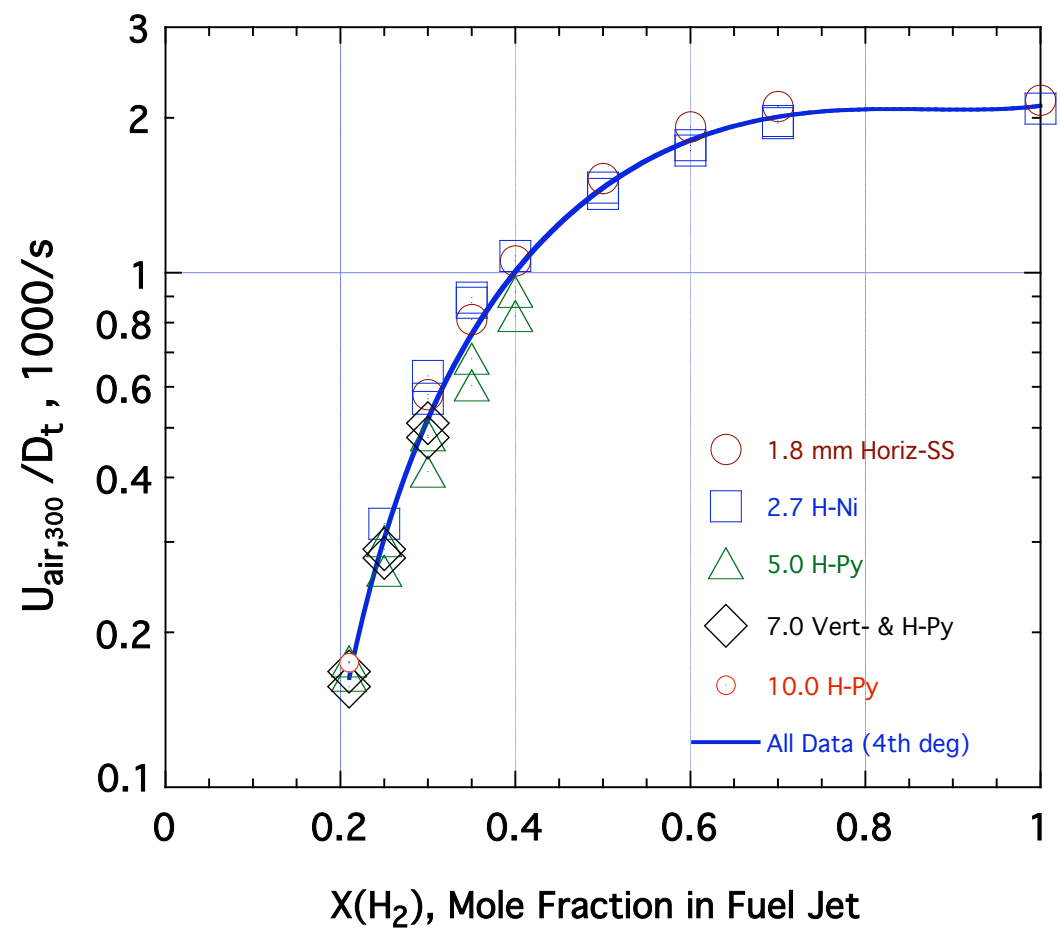

Fig. A6. Applied Stress Rates (ASR) for extinction of $\mathrm{H}_{2} / \mathrm{N}_{2}-$ Air CFDFs using tube-OJBs; fuel and airside edge of flame at $300 \mathrm{~K}$. 


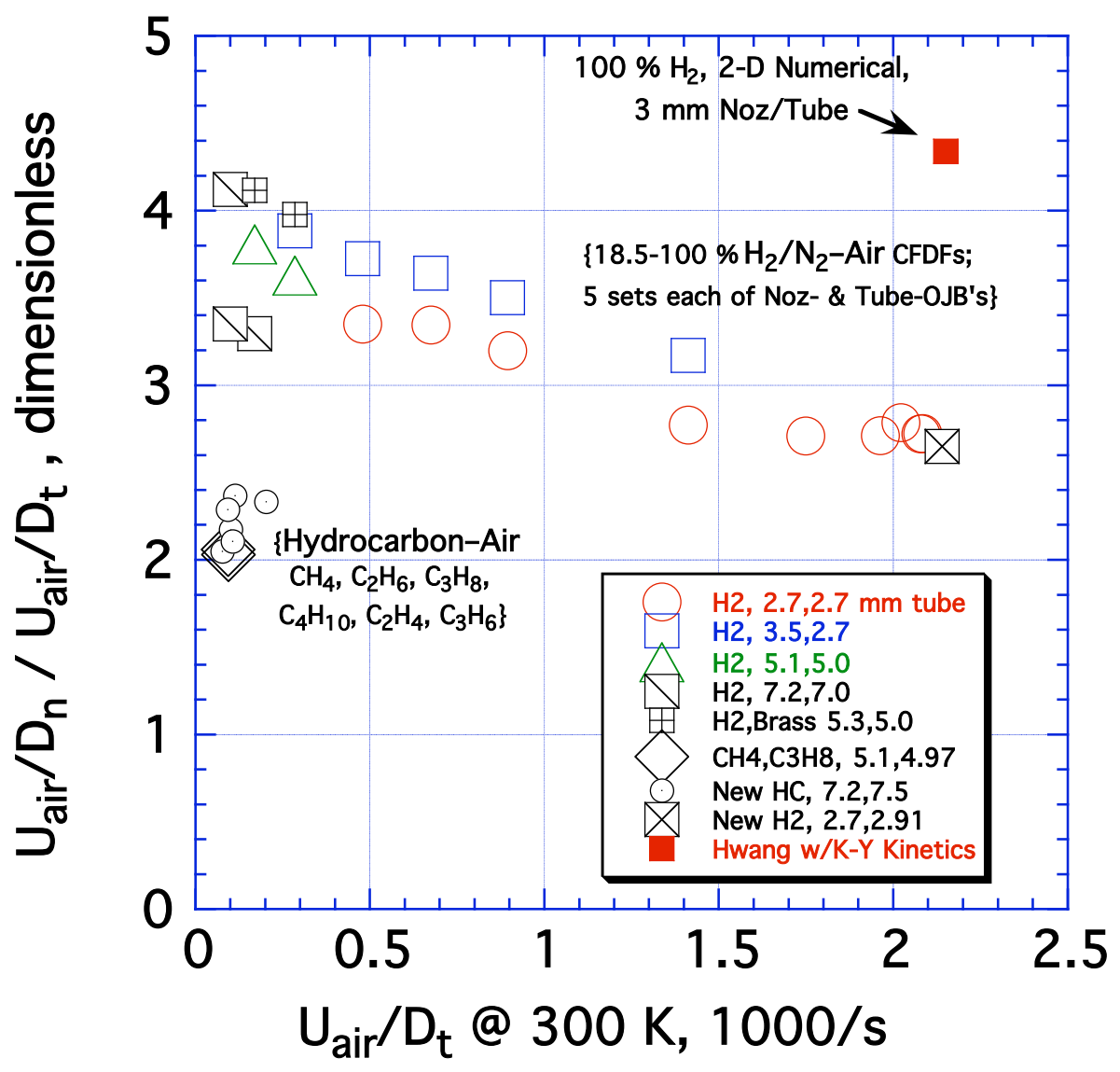

Fig. A7. Summary plot of ratio of Applied Stress Rates at extinction for nozzle-OJBs / tube-OJBs, as a function of ASR for tube-OJBs, for hydrogenair and hydrocarbon-air data. 